\title{
WestVirginiaUniversity
}

THE RESEARCH REPOSITORY @ WVU

Graduate Theses, Dissertations, and Problem Reports

1991

\section{Development of a measure of therapist trustworthiness}

\author{
Gregory M. Alberts \\ West Virginia University
}

Follow this and additional works at: https://researchrepository.wvu.edu/etd

Part of the Counseling Psychology Commons

\section{Recommended Citation}

Alberts, Gregory M., "Development of a measure of therapist trustworthiness" (1991). Graduate Theses, Dissertations, and Problem Reports. 3756.

https://researchrepository.wvu.edu/etd/3756

This Dissertation is protected by copyright and/or related rights. It has been brought to you by the The Research Repository @ WVU with permission from the rights-holder(s). You are free to use this Dissertation in any way that is permitted by the copyright and related rights legislation that applies to your use. For other uses you must obtain permission from the rights-holder(s) directly, unless additional rights are indicated by a Creative Commons license in the record and/ or on the work itself. This Dissertation has been accepted for inclusion in WVU Graduate Theses, Dissertations, and Problem Reports collection by an authorized administrator of The Research Repository @ WVU.

For more information, please contact researchrepository@mail.wvu.edu. 
DEVELOPMENT OF A MEASURE

OF THERAPIST TRUSTWORTHINESS

\section{DISSERTATION}

Submitted to the Graduate School

of

West Virginia University

In Partial Fulfillment of the Requirements for

The Degree of Doctor of Philosophy

by

Gregory Martin Alberts, M.A.

Morgantown

West Virginia

1991 


\section{ACKNOWLEDGEMENTS}

I'm glad this is finished, because now everything will be oK. Yeah, Easy street. And of course, the obligatory Mother of All Thanks is due to those whose direct and indirect participation in this project (finally) resulted in its completion. First, maximum gratitude to Barry Edelstein, whose capacity as mentor, chairperson, friend, host, plus good and bad (in a good way) role model, has served to shape my psyche (oxymoron) in many significant ways. Second, thanks to stan Cohen, Bill Cormier, David Hansen, and B. Kent Parker for their smart advice and congenial comportment during my proposal and defense meetings. Third, an extreme amount of indebtedness is due the patients and therapists whose genuine interest and willing participation in this study were, by far, the most gratifying and least complicated elements of this (at times torturous) project. Fourth, thanks to my parents, whose emotional, financial, genetic, editorial, and other contributions to me (and to this project) have made Life easier. And last, quite simply, to Me. 
Table of Contents

ACKNOWLEDGEMENTS $\ldots \ldots \ldots \ldots \ldots \ldots \ldots \ldots \ldots \ldots \ldots \ldots \ldots \ldots \ldots$

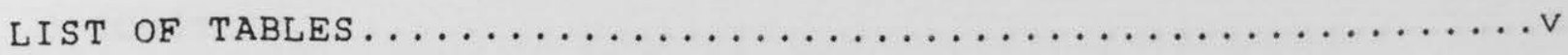

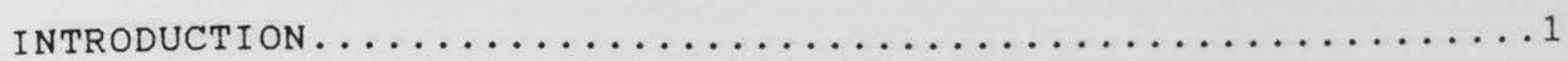

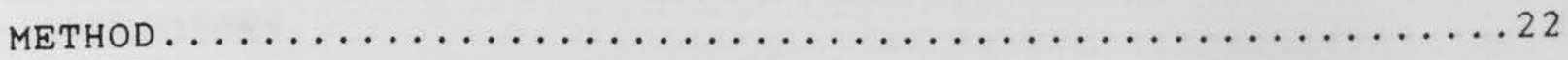

STAGE I : ITEM DEVELOPMENT .................... 22

procedure.......................... 22

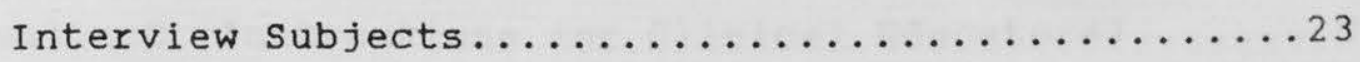

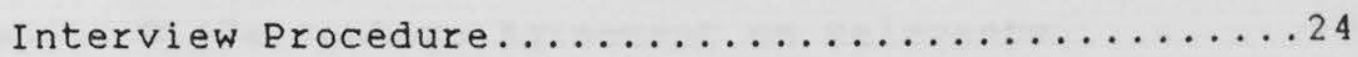

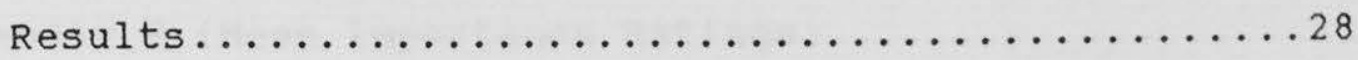

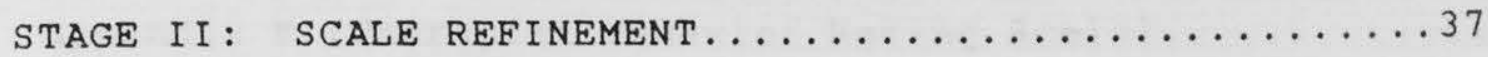

Item Ratings by $\mathrm{Client}$ Judges.............. 37

subjects.............................

Rating Procedure..................... 38

Ratings by clinical Educators.............. 41

subjects............................ 41

Rating Procedure..................... 42

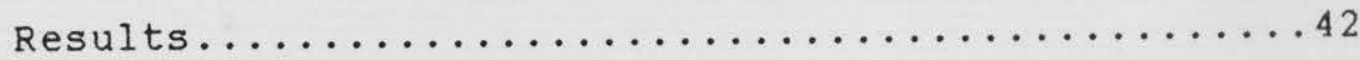

STAGE III: PRELIMINARY PSYCHOMETRIC EVALUATION $\ldots \ldots \ldots 46$

subjects............................ 46

Procedure ............................ 48

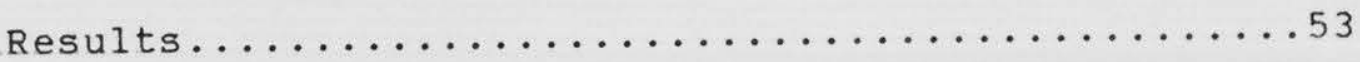

General scale Characteristics............53

Scale Reliability.................... 56

Validity Analyses................... 56 
Multiple Regression................61

Dimensionality study................ 61

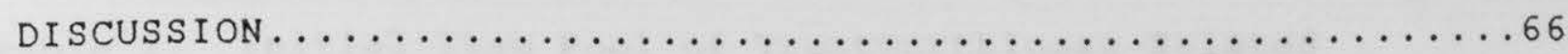

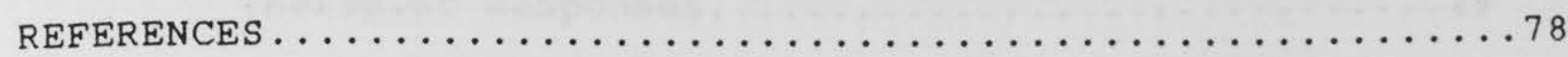

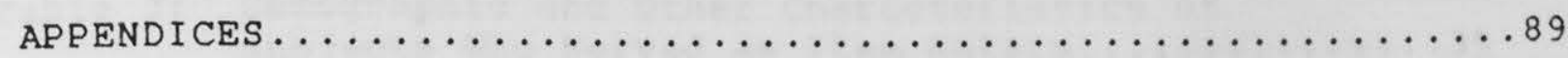

Appendix A (Interview Outline) ..................

Appendix B (stage II Rating Materials) ............

Appendix C (Instructions for Clinical Educators).......99

Appendix D (Percentage Agreement on Relevance).......102

Appendix E (Mean Importance Ratings) ..............111

Appendix F (Therapist Behavior Rating Scale).........117

Appendix G (Client-Completed Rating Materials).......120

Appendix H (Therapists' Rating Materials)...........123

Appendix I (Factor Labels, Items, \& Item Loadings)....125

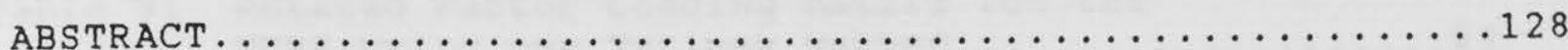




\section{LIST OF TABLES}

Table 1: Demographic and other Characteristics

of Interview subjects................... 25

Table 2: Initial Item Pool of Trustworthiness-Related

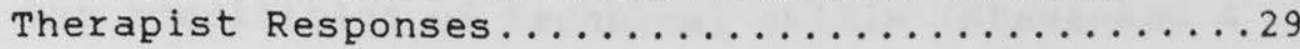

Table 3: Demographic and other Characteristics of subjects who served as Item Raters...............39

Table 4: Demographic and Professional Characteristics of Therapists...................... 47

Table 5: Demographic and other Characteristics of

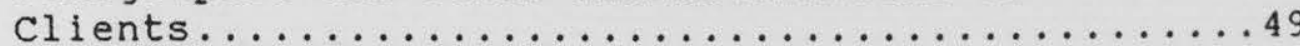

Table 6: Descriptive statistics for TBRS Scores by Individual Therapist................. 54

Table 7: Item Means, Standard Deviations, and Corrected Item-Total Correlations...........57

Table 8: Pearson Correlation Coefficients of Total TBRS Scores With Patient status Ratings and Therapy Process Ratings From Client and Therapist Perspectives.............59

Table 9: Rotated Factor Loading Matrix for the TBRS Using the Varimax Method............664 


\section{Development of a Measure of}

Therapist Trustworthiness

Graduate and professional therapist training programs emphasize the acquisition of technical skills (stevenson \& Norcross, 1987) and deemphasize the promotion of interpersonal and relationship competencies (Lambert, 1989; Schiffman, 1987). The content of such training programs and the procedures by which the competencies of prospective mental health practitioners are developed and evaluated have been criticized because neither are based on an adequate fund of clinically relevant empirical knowledge (Ford, 1979; Garfield, 1977; Matarazzo, 1978; Ponterotto \& Furlong, 1985; Scofield \& Yoxtheimer, 1983).

Ford (1979), in what is perhaps the most widely cited review of therapist training research, concluded that the dependent variables employed in most training outcome studies had not been validated. The types of dependent variables frequently employed in training investigations are not selected on the basis of empirical criteria, but are chosen because they fit with the conceptual framework or counseling approach of the investigator (Hill, 1982; Matarazzo, 1978). Given the questionable foundation underlying the content and process of current training practices, Hirschenberger, McGuire, and Thomas (1987) asserted that "it is impossible to determine for any given graduate whether the competencies have been developed that are essential for protecting client rights while providing 
effective treatment" (p. 317).

Effective treatment is the product of a complex interaction of patient characteristics, therapist attributes, clinical procedures, and contextual elements that, at present, are only partially understood. Focusing on therapist variables that are related to patient improvement has been suggested to be a logical step in the development of clinically valid dependent variables for training (e.g., Collins, Foster, \& Berler, 1986).

In a commentary on the therapeutic components shared by al1 successful psychotherapies, Frank (1982) noted that, in large part, the "determinants of therapeutic success lie in the personal qualities of and the interaction between patient and therapist [rather] than in the particular therapeutic method used" (p. 15). Frank's assertion that treatment outcome is more a product of relationship dynamics than of methodological factors is not without empirical support. A number of reviewers who have summarized the empirical data regarding the process and effects of psychotherapy have concluded that therapist factors consistently appear to be significantly more influential in contributing to outcome than is the brand of therapy or the specific intervention techniques employed (e.g., Beutler, Crago, \& Arizmendi, 1986; Lambert, Shapiro, \& Bergin, 1986; Luborsky, Singer, \& Luborsky, 1975; Orlinsky \& Howard, 1986; Parloff, Waskow, \& Wolfe, 1978; Smith, Glass, \& Miller, 1980). Although some have argued that the absence of 
consistent or convincing findings that different treatments lead to differential effectiveness can be explained by limitations in methodology and in the nature of the hypotheses that such outcome studies test (e.g., Beutler, 1991).

Regardless of this debate, the importance of the interpersonal context of treatment is widely recognized among virtually all schools of therapy, despite their widely differing theoretical and technical features (Gurman, 1977).

Various taxonomies of change-relevant therapist factors have been proposed to understand and organize research on the treatment process (e.g., Beutler, Crago, \& Arizmendi, 1986; Lambert, 1989; Strupp, 1977). A representative framework offered by Beutler et al. (1986) organizes therapist factors on two dimensions. The first dimension, termed "extratherapy" characteristics contains factors that are considered to exist independent of, and coincident to, the actual therapy context (e.g., therapist age, gender, and emotional well-being). These factors are distinguished from "therapy-specific" variables which are posited to have a more direct impact on the treatment process (e.g., professional orientation, intervention skills, level of verbal activity).

The level of inference required to measure variables contained in each of these classes is the second taxonomy dimension. Low inference or "externally observed" variables are amenable to direct measurement and are readily quantified (e.g., gender), whereas high inference "inferred, internal" 
variables require a greater degree of extrapolation in measurement (e.g., therapist expectations).

The class of relationship promoting therapist variables of most relevance to clinical educators is the dimension targeting therapy-specific characteristics. Unlike extratherapy factors, variables within this dimension are amenable to change via training (e.g., Alberts \& Edelstein, 1990; Hill, Charles, \& Reed, 1981; Thompson, 1986). Questions regarding how these therapist characteristics interact with other treatment elements and which of these variables are more important than others in accounting for relationship enhancement have not been answered decisively. Rogers (1957), one of the earliest pioneers in the area of therapist factor research, focused attention on variables related to clients' perceptions of three "primary" relationship conditions: empathy, warmth, and genuineness. Goldstein, Heller, and sechrest (1966) have suggested that the client's evaluation of the therapy relationship was controlled largely by therapist behaviors that were indicative of such characteristics as expertness and credibility. Similarly, strong (1968) proposed that clinicians who are perceived by their clients as expert, attractive, and trustworthy are more likely to establish a relationship that enhances their capacity to influence the client in a therapeutic direction.

The contribution to the treatment process made by these variables and other related therapist factors has been judged 
positively by most reviewers of this literature (e.g., Barrett \& Wright, 1984; Goldstein, 1971; Gurman, 1977; Heppner \& Dixon, 1981; Lambert \& Bergin, 1983). However, as these reviewers generally caution, the paucity of discriminative operational definitions of these respective constructs, the correlational and post-hoc nature of most study designs, and the use of measures of marginal psychometric integrity are among the methodological limitations that temper the specificity and strength of the conclusions that can be drawn from empirical studies of these variables.

\section{Therapist Trustworthiness as a Critical Variable}

The client's perception that his or her therapist is trustworthy is noted to be one of the most critical features of effective helping relationships (e.g., Cormier \& Cormier, 1985; Greben, 1984; Egan, 1986; Frank, 1959; Strong, 1968; Strupp, 1973; Tyler, 1965). Frank (1959) asserted that the client's attitude of trust toward the therapist is a requisite condition for a positive response to treatment. Tyler (1965) underscored the importance of trust by stating that "the client's confidence in the counselor, the assumption that he can believe what this person tells him, is the essential foundation for the whole counseling process" (p. 16). Strupp (1973) echoed similar sentiments regarding the centrality of trust'by' stating:

In short, the interpersonal strategies lof the patient]... are techniques for warding off trust in 
significant others...

Thus, psychotherapy is a series of lessons in

basic trust, together with the undermining of those interpersonal strategies the patient has acquired for controlling himself and others. (p. 138)

The client's trust in his therapist is thought to influence a variety of important outcomes during the course of clinical assessment and change efforts. Cormier and Cormier (1985) have proposed that the implications for a therapist's perceived trustworthiness vary, in part, on the particular phase of therapy. For example, at the very outset of treatment, a therapist who is seen as trustworthy will be more likely to succeed in the crucial task of establishing rapport with the client. During the assessment and goal formulation stages of therapy, the client's self-exploration and selfdisclosure of problem information is thought to be governed by the degree to which the therapist is seen as trustworthy (Cormier \& Cormier, 1985). Self-revealing communication of sufficient breadth and depth is considered a sine qua non for adequate problem assessment and case formulation (Kanfer \& Goldstein, 1975).

The therapist's perceived trustworthiness may serve to enhance the client's motivation to accept change and to better process the concomitant feelings of vulnerability and uncertainty that may arise in the phase of treatment during which therapeutic techniques are actively implemented (Cormier 
\& Cormier, 1985). Consequently, the client's acceptance, involvement, and collaboration in the problem-solving elements of treatment make him more amenable to change (Kanfer \& Goldstein, 1975; Fong \& Cox, 1983). Finally, during the termination phase of therapy the client's trust in the therapist facilitates both his/her acceptance that the treatment relationship is ending and his/her transition to more independent functioning (Cormier \& Cormier, 1985). Fong and Cox (1983) have suggested that the therapist's perceived trustworthiness may even reduce the likelihood of clients terminating therapy prematurely.

Factors Accounting for Perceptions of Trustworthiness

Not unlike theorists in the fields of social and personality psychology, whose definitions of trustworthiness invoke concepts such as reliability (Rotter, 1971), dependability and predictability (Rempel, Holmes, \& Zanna, 1985), confidentiality (Johnson-George \& Swap, 1982), and honesty and benevolence (Larzelere \& Huston, 1980), clinical and counseling psychologists similarly have invoked a variety of reputational, role-based, and interpersonal features to account for perceived therapist trustworthiness.

The therapist's social role and reputation are thought to weigh heavily in a client's initial assessment of trustworthiness (strong, 1968). For example, at the very outset of a treatment relationship, perceived trustworthiness might be influenced by knowledge that the client has acquired 
from friends or other sources pertaining to therapists' ethical mandate to maintain confidentiality. Similarly, it is widely held that compassion and sensitivity are characterological features descriptive of individuals in vocational roles involving care provision. As is frequently the case, referrals of patients to specific mental health professionals often come from friends or family members who have themselves had contact with the referred practitioner. If the referred practitioner is imbued with positive attributes, then it is probable that this reputational endorsement will positively influence perceived trustworthiness.

The authors of several popular counselor education texts have stipulated a variety of interpersonal behaviors thought to be involved in validating and maintaining the client's perception that a therapist can be trusted, if their initial evaluation of trustworthiness is satisfied (e.g., Cormier \& Cormier, 1985; Kanfer \& Goldstein, 1975). Cormier and Cormier (1985) have suggested that an important element in conveyed trustworthiness is the degree to which the therapist demonstrates a high level of "congruence" between verbal and non-verbal channels of behavior. That is, if a therapist says that he/she is interested in hearing what the client's reaction to a particular event was, then he/she should look as if he/she were interested. The manner of non-verbal acceptance of client disclosures and non-vocal behavioral styles referred to as "responsiveness" and "dynamism" also are thought to play 
important roles. Other responses that Cormier and Cormier (1985) have suggested contribute to perceptions of trustworthiness include accurate paraphrasing, accurate and reliable information provision, and openness and honesty. Additional trust-facilitating responses pertain to maintaining confidentiality, demonstrating dependability, and following through on expressed commitments. However, the authors rely primarily upon clinical wisdom and theory when discussing verbal and other corresponding behavioral features that constitute many of the above responses.

Kanfer and Goldstein (1975) have indicated that therapist behaviors are trustworthy to the extent that they serve to minimize the client's fears of "exploitability." strong (1968), likewise, has noted that therapist behaviors that are indicative of a lack of motivation for personal gain are crucial to conveying trustworthiness. Kanfer and Goldstein (1975) have also suggested that clients' fears of rejection are minimized and trustworthiness is projected when the therapist responds to self-disclosures with "acceptance," that is, communicates accurate understanding and then follows with a reciprocal disclosure of "such information as his perceptions of the client and his reactions to what is taking place within the helping situation" (p. 58). Greben (1984), likewise, has stated that providing feedback to the patient about the process of treatment and using such opportunities to communicate a sense of "realistic hopefulness" for therapeutic improvement 
positively influence perceived trustworthiness.

In one of the more thorough discussions to date on this topic, Fong and Cox (1983) have suggested that the level of trust held by clients is best conceptualized as falling on a continuum, anchored on the positive end by blind unquestioning faith and contrasted by complete suspicion and distrust on the negative end. They defined trustworthiness as "the client's perception and belief that the counselor will not mislead or injure" him or her in any way (p. 163). As active processors of interactional events, clients are said to draw conclusions about their therapists' motivations by monitoring behavioral responses to direct and indirect "tests of trust." The reactional probes delivered by clients ostensibly provide them with an opportunity to "gather empirical data to determine whether their working hypothesis ('this counselor is trustworthy') is valid" (p. 163). Such probes may take the form of a simple favor or request or they may be less direct and involve blatant self-denigrating disclosures. When the counselor accurately recognizes the client's trust probes and responds appropriately, a workable relationship presumably can then develop. Conversely, if the counselor fails to detect accurately these tests of trust or if the counselor's responses to these probes are ineffective, (i.e., superficial or defensive), then the relationship is said to be at risk for deteriorating. 
accounts of therapist variables involved in conveying trustworthiness. Initially, trustworthiness is best

represented as a judgment or assessment by the client regarding the therapist. Trustworthiness is defined and exists in the perceptual realm of client rather than in the corporeal or psychological realm of the therapist. To borrow:

trustworthiness lies in the eye of the beholder and does not comprise the beholden. As such, trustworthiness can be construed as the labeling of a response style that references certain aspects of the therapist's interpersonal manner rather than being an inherent property or attribute of the therapist (i.e., a trait). It follows from the literature cited above that what is referenced by the client in the assessment of trustworthiness are therapist behaviors or responses classes (both verbal and non-verbal) that convey some (or all) of the following:

1. That the therapist is genuinely concerned about the welfare of the client and is motivated solely by this concern to benefit the client.

2. That the therapist respects and does not judge the client despite the client's present inability to adjust to the demands of his/her life circumstances.

3. That the therapist is understanding and comprehends the nature of the client's concerns and needs. 
4. That the therapist credibly communicates his/her capacity to assist the client in improving his/her situation and is optimistic about a positive outcome.

5. That the therapist is honest, reliable, and can be depended upon to do what he/she says.

The Measurement of Therapist Trustworthiness

Approaches to the measurement of therapist trustworthiness have taken two directions in the literature. Initially, in a small sample of analogue studies in the early 1970's, simulated counseling interviews and videotaped counseling vignettes served as stimuli for judges to provide simple Likert-type scale evaluations of the extent to which the portrayed interviewers were trustworthy ( Kaul \& Schmidt, 1971; Roll, Schmidt, \& Kaul, 1972; Strong \& Schmidt, 1970).

Kaul and Schmidt (1971) had 32 undergraduate and graduate students rate the trustworthiness of actor-portrayed counselors in a series of brief simulated interviews. Employing a simple factorial design, groups of subjects were presented with interview segments depicting trustworthy or untrustworthy verbal responses which were delivered in either a trustworthy or untrustworthy non-verbal manner. The authors concluded that (a) the non-verbal demeanor of actors was generally a stronger determinant of subjects' trustworthiness ratings than was the verbal interview content; (b) there were no differences between male and female raters; and, (c) subjects who were given a 
definition of trustworthiness prior to observing the tapes provided significantly lower ratings than subjects who did not receive the definition.

In a field extension of this investigation, Roll, schmidt, and Kaul (1972) examined cross-cultural differences in the perceptions of counselor trustworthiness among 36 penitentiary inmates, half of whom were African American and half of whom were caucasian. Subjects were matched on grade level, age, IQ and academic achievement. There were no significant interracial differences found, nor did providing subjects with a definition of trust lead to differential ratings. However, when the interview verbal content and the manner of non-verbal delivery were discrepant (e.g., trustworthy responses delivered in an untrustworthy style), non-verbal variables exerted more control over subjects' ratings than did verbal content.

One of the few other trust-related studies was conducted by strong and schmidt (1970). These investigators attempted to evaluate the influence of therapists' perceived trustworthiness on their ability to influence achievement motivation in single analogue counseling interviews with undergraduates. Manipulations of counselors' perceived trustworthiness via initial introductions (confidential versus unconfidential), and interviewer performance variables (trustworthy versus untrustworthy verbal and non-verbal responses), were not successful and resulted in positive trustworthy evaluations for counselors in all conditions. Due to the ineffective 
manipulation, the effect of trustworthiness on interpersonal influence could not be measured.

A second measurement tradition was established with the development of several more elaborate rating scale instruments, such as the Counselor Rating Form (CRF; Barak \& LaCrosse, 1975), the Counselor Evaluation Rating Scale (CERS; Atkinson \& Wampold, 1982), and the Counselor Interview Competence Scale (CICS; Jenkins, 1982). The CRF (Barak \& LaCrosse, 1975) was developed to measure the constructs that strong (1968) suggested mediated counselors' social influence in therapy: expertness, attractiveness, and trustworthiness. The CRF consists of 36 adjectives selected from a larger pool of adjectives thought to be representative of the three attribute dimensions. Subjects make ratings on 7-point bipolar scales anchored by each of the 36 adjectives and their opposites.

There is a consensus of reservations in the literature regarding the validity of the CRF as a measure of therapist trustworthiness. Questions about the validity of the CRF come not only from independent reviewers (e.g., Corrigan \& Schmidt, 1983; Heesacker \& Heppner, 1983; Ponterotto \& Furlong, 1985; Scofield \& Yoxtheimer, 1983; Zamostny, Corrigan, \& Eggert, 1981), but also from the developers of the CRF as well (Lacrosse, 1977; Lacrosse \& Barak, 1976). In a critical review of counselor rating scale instruments, Ponterotto and Furlong (1985) noted that despite more than 20 years of research with the CRF, data in support of the validity of this instrument are 
minimal at best. Basing their criticisms on the results of a large body of correlational studies and factor analytic investigations, they found that interscale correlations among the supposedly distinct dimensions of attractiveness, expertness, and trustworthiness subscales were consistently high. For example, the mean of the correlations between trustworthiness and expertness subscales across 35 reviewed studies was .77 , while the mean of the correlations between trustworthiness and attractiveness subscales was .73.

The high interscale correlations reported in the these investigations suggest that the CRF is a unidimensional measure of client perceptions of counselor behavior (Gilbert, Lee, \& Chiddix, 1981; Heesacker \& Heppner, 1983; LaCrosse, 1977; Zamostny et al., 1981). Additional factor analytic studies of the CRF have provided further evidence for a more global, singular factor. Heesacker and Heppner (1983), for example, found that clients who rated their therapists at the close of counseling "do not clearly distinguish among perceived counselor expertness, attractiveness, and trustworthiness" (p. 185). Likewise, on the basis of client perceptions taken at the onset of counseling, Zamostny et al. (1981) concluded that "perceptions may have reflected an overriding good guy factor..." (p. 487). Lacrosse (1977) has proposed that the three counselor attributes ostensibly measured by the CRF could perhaps be subsumed under a broader unitary perceptual dimension of "credibility." 
In light of the statistical evidence bearing on the poor construct validity of the CRF (in the measurement of therapist trustworthiness), Corrigan and schmidt (1983) revised the measure in an attempt to improve its capacity to differentiate among counselor attributes. Four items from each of the three subscales of the CRF were included in the revised scale (Counselor Rating Form-Short version; CRF-S). Items were selected on the basis of their consistently high intrascale loadings on the respective dimensions as determined in previous factor analytic studies. According to Ponterotto and Furlong (1985), had Corrigan and Schmidt (1983) more appropriately considered the magnitude of interscale loadings as a selection criterion, none of the four trustworthiness items would have been selected. On the issue of the CRF-S as a measure of counselor trustworthiness, they concluded that there are "serious questions about the independence of the trustworthiness construct...pending the outcome of further research, the trustworthiness scale will require additional modifications before its utility for counseling research can be determined" (p. 606).

Another counselor competency instrument, the counselor Effectiveness Rating Scale (CERS; Atkinson \& Wampold, 1982) was developed to provide a multidimensional measure of counselor effectiveness, not unlike the measurement objectives of the CRF and CRF-S. Similarly, the CERS targets for measurement the social influence attributes of expertness, attractiveness, and 
trustworthiness (strong, 1968). Noting that the CERs was used only 8 times in published studies in the 11 years following its development, Ponterotto and Furlong (1985) indicated that the scale is subject to the same validity concerns noted for the CRF and CRF-S. In short, the lack of factor independence and the overall paucity of data addressing the psychometric properties of this instrument limit its utility as a measure of trustworthiness.

Unlike the three previous rating scales, the Counselor Interview Competence Scale (CICS; Jenkins, 1982) requires that trained raters make judgments of various counseling competencies, one of which is the degree to which interviewers appear trustworthy. The CICS has been employed in three analogue studies (Baker, Johnson, Kopala, \& Strout, 1985; Baker, Scofield, Clayton, \& Munson, 1984; Baker, Scofield, Munson, \& Clayton, 1983), none of which had the evaluation of its measurement properties as an a priori goal. While there is some evidence from these studies that extensively trained raters using the CICS were able to differentiate reliably between counselors of varying competence levels, the validity of individual scale dimensions (i.e., trustworthiness), has not been demonstrated.

The Rationale Behind the Development of a New Measure

Previous attempts to construct instruments to measure therapist trustworthiness have not been wholly successful. Problems in the measurement of therapist trustworthiness appear 
to be due to several factors, including an overreliance on a particular theory to guide scale construction (Ponterotto \& Furlong, 1985), or more generally, a lack of methodological sophistication regarding the design and validation of such instruments (Scofield \& Yoxtheimer, 1983). In these previous measurement attempts, trustworthiness has been conceptualized in non-operational and trait-like terms. Because trustworthiness has been conceptualized from a trait perspective, the available measurement instruments solicit global and impressionistic evaluations of the trustworthiness and related attributes of counselors and clinicians. Regarding item development and selection strategies, scale developers have discounted, for the most part, the role of specific therapist behaviors and interpersonal responses that the literature suggests might be crucial for influencing clients' perceptions of trustworthiness. Subsequently, the utility of these instruments for use in training and other applications is I imited.

The development of a reliable and valid instrument for measuring therapist trustworthiness is warranted for several reasons. First, a clinician's ability to behave in ways that influence clients' perceptions of trustworthiness is an important clinical competency. Given the purported role that therapist trustworthiness plays in relationship development and the treatment process, a means of measuring the skills and behaviors that relate to this phenomenon is essential. Gurman 
(1977) has noted the following about psychotherapy research:

[It] must attempt to explicate what it is that the therapist does in the therapist-patient transaction that communicates his "attitudes" of involvement, caring, and non-defensiveness... [because] the future training of effective psychotherapists must have an empirical base which allows specification of the therapist behaviors that are likely to communicate these and other facilitative conditions. (p. 537)

An instrument that reliably and accurately measures the behavioral components of therapist trustworthiness will aid in the evaluation and training of prospective counselors and clinicians.

second, the systematic investigation of therapist trustworthiness and its relation to various other process and outcome variables has been hampered by the lack of a valid measurement instrument. The effects of therapist trustworthiness during assessment and treatment phases of therapy, for the most part, has been speculative. Thus, a measure of trustworthiness might facilitate the empirical examination of the functions of trustworthiness.

Third, measures that assess client perceptions of treatment process variables may have value as clinical tools for use by practitioners. Periodic solicitation of client feedback via a trustworthiness scale might alert the clinician to deficiencies in his/her relationship with the client and cue 
him/her to consider remedial strategies.

The present study was designed, therefore, to construct a rating scale that would assess specific therapist behaviors that are perceived by clients as trustworthy. The rating scale was designed to be completed by clients following therapy sessions. Throughout the process of scale construction, opinions, observations, and evaluative judgments provided by clients significantly influenced the content, format, and other important characteristics of the measure. The active contribution by clients to the process of scale construction was so engineered because they are in a position to give first hand information on how a therapist's interpersonal behavior is experienced. Although client ratings are often at variance with ratings obtained from other sources and perspectives (e.g., the therapist or trained observers), they are considered to be fundamental to the assessment and understanding of treatment process and outcome (cf. Beutler, Crago, \& Arizmendi, 1986; Strupp \& Hadley, 1979). In fact, a number of researchers have suggested that patient ratings of in-session events may provide more useful and reliable data than those based on the judgments of external observers (e.g., Beutler, Johnson, Neville, \& Workman, 1973; Gurman, 1973; Mintz \& Luborsky, 1971). Further, the "naivete" of the client permits him/her to make judgments that are not biased by theoretical preconceptualizations.

Following scale construction, a clinical sample of 
therapist-client dyads were recruited to participate in the initial psychometric evaluation of the present measure. In addition to conventional reliability and validity estimates, a factor analytic study was performed to examine the underlying structure of ratings on the scale. 


\section{STAGE I: ITEM DEVELOPMENT}

\section{Method}

\section{Overview}

Stage I involved the development of a large pool of items for subsequent evaluation and possible inclusion in the final version of the scale. The adaptation of items from existing trust-related measures, the formation of items based on subject interviews, and "rational" item writing were the primary item development strategies employed.

\section{Procedure}

The first step in item development involved examining the content of the few existing scales in the therapist evaluation literature which purport to measure some aspect of trust or trustworthiness in treatment relationships. The scales reviewed included the Counselor Rating Form (Barak \& LaCrosse, 1975), the Counselor Evaluation Rating Scale (Atkinson \& Wampold, 1982), and the Counselor Interview Competence Scale (Jenkins, 1982). Items from therapist rating scales or therapy process measures targeting the treatment "alliance" and related constructs also were used as stimuli for item construction. The reviewed scales included the Working Alliance Inventory (Horvath \& Greenberg, 1986), the Therapeutic Bond Scales (Saunders, Howard, \& Orlinsky, 1989), the Helping Alliance Rating Scale (Morgan, Luborsky, \& Crits-Cristoph, 1982), and the Relationship Inventory (Barrett-Lennard, 1962). Additionally, several measures targeting trust in non-clinical 
interpersonal relationships were appraised. These measures included the Dyadic Trust scale (Lazelere \& Huston, 1980), the Trust Scale (Rempel, Holmes, \& Zanna, 1985), and the Specific Interpersonal Trust Scale (Johnson-George \& Swap, 1982).

Second, Dawes (1987) has suggested that a useful adjunct to adaptational and rational item writing approaches is to gather descriptions of the variable of interest from subjects representative of the population who ultimately will respond to the measure. Because scale constructors often generate items contaminated by technical terms or jargon, construct descriptive statements elicited via interviews potentially can enhance the "authenticity" (i.e., face or content validity) of a measure. To this end, semi-structured interviews were conducted with a sample of psychotherapy patients and individuals without a history of psychotherapy participation. The rationale for selecting these subject groups is described below.

\section{Interview subjects}

A total of 17 subjects participated in item-generation interviews. Eight of these subjects were participants in ongoing therapy and the other nine were not in therapy and had no previous history of mental health treatment. Current therapy clients were included as subjects because it was assumed that their opinions and observations, in part, would reflect their experience of having trusted (or having not trusted) a therapist. The sample of "naive" or no-therapy experience 
subjects was included to learn of the possible expectations that clients-to-be have regarding trustworthy responses of therapists. Additionally, the input from these subjects potentially would enhance the measure's applicability to client-therapist pairs who were in the earliest stage of relationship development.

Eleven subjects of this total sample were recruited from an outpatient psychiatry clinic of a 250 bed university-based general hospital. Eight of the 11 subjects from this site were current psychotherapy patients; the other 3 subjects, who were without psychotherapy histories, were recruited from the clinic waiting 1 ist so that they could be interviewed prior to their initial appointment. The remaining six subjects, all of whom were without psychotherapy histories, were recruited from a community-based support group whose primary mission was to disseminate information to individuals contemplating mental health treatment. Demographic information and other characteristics of these interview participants can be found in Table 1.

\section{Interview Procedure}

At the request of the clinic director, the trustworthiness interviews with the wait-listed clinic patients were conducted over the telephone, rather than in person, in order to ensure that participants did not confuse the study with the treatment activities of the clinic. (One interview was conducted in a clinic office because of a subject's request to 
Table 1

Demographic and other Characteristics of Interview subjects

Characteristic

Psychotherapy status

Current Patient No History

Mean Age (years)

44.4

34.5

Sex

Female

4

6

Male

4

3

Race

Caucasian

8

9

other

0

0

Marital status

single

3

6

Married

5

3

Mean Years of Education

14.8

13.3

Yearly Income

$$
\begin{aligned}
& \text { Under } \$ 10,000 \\
& \$ 10,001-20,000 \\
& \$ 20,001-30,000 \\
& \$ 30,001-40,000 \\
& \text { over } \$ 40,000
\end{aligned}
$$$$
2
$$ 
keep his participation anonymous from family members.)

Additionally, interviews with the six subjects recruited from the community support group were conducted over the telephone. Interviews lasted from 20 to 50 minutes. Eleven of the interviews were audiorecorded; the remainder were not because of subject refusal or hesitancy to be taped.

The goal of the interviews was to gather from subjects descriptions of therapist responses that facilitated or interfered with trust development in psychotherapy relationships. The interviews were conducted by the author who used a series of "trustworthiness probes" to impose some structure on the conversation. The content of the trustworthiness probes largely was based on what psychotherapy trainers and psychotherapy process researchers have written regarding the psychotherapeutic conditions and the qualities and attributes of helpers that convey trustworthiness. Commonly cited attributes include such interpersonal characteristics as honesty, sincerity, credibility, acceptance, reliability, and confidentiality (e.g., Cormier \& Cormier, 1985; Fong \& Cox, 1983; Kanfer \& Goldstein, 1975). For example, the probe: "Think of some specific examples of how a therapist might talk or act with you which suggest that $s /$ he is concerned about you and won't judge what you say," was a question inquiring about sincerity and the non-judgmental aspects of therapists. The interview outline can be found in Appendix A. 
Following each interview the author transcribed those portions of the conversation that were felt to be relevant and usable for formulating items (i.e., descriptions of an insession therapist communication or action that the respondent indicated influenced his or her ability to trust a therapist).

Several a priori considerations affected the implementation of the item generation strategies and subsequent item content. Principal among these considerations was an overall goal to create items that were descriptive of the insession interpersonal behavior and conduct of therapists. Consistent with this goal was an attempt to produce items that would not emphasize highly inferential characterologic dimensions of a therapist's manner or style. Abiding by these guidelines presumably would enhance the scale's prescriptive utility for training purposes. Additionally, an attempt was made to not let any specific theory of therapy or counseling approach explicitly govern item development. This, in part, was accomplished by relating items to the interpersonal conduct of therapists rather than to specific therapeutic techniques or activities. Throughout this item-generation process it was essential to account for therapist responses that facilitated and, as well, detracted from trust development in psychotherapy relationships. During item writing the following questions of each potential item often were asked: (a) "Could a client or independent observer witness a therapist doing or saying this?" and, (b) "Is this a response that a therapist could acquire 
through training?"

The item generation strategies resulted in the construction of 75 items. Forty-two were worded to capture responses that facilitated trustworthiness and the remaining 33 were worded to reflect responses that decreased trustworthiness. Items were randomly ordered into a 1 ist, checked for linguistic and spelling errors and analyzed for readability and comprehension.

\section{Results}

The complete randomly ordered item list is shown in Table 2. Noted next to each item is the valence of the response (i.e., positive or negative as judged by the author). The assessment of the readability and grade level of the item list was conducted by a commercially available grammar and linguistic analyzer for personal computers (Grammatik III). A Flesch Reading Ease index of 83 and a Flesch-Kincaid Grade Level of 4.0 were obtained indicating that the scale was suitable for individuals with limited education. 
Table 2

Initial Item Pool of Trustworthiness-Related Therapist

\section{Responses}

Item

Valence

1. He indicates that he won't judge me or

criticize me no matter what I say.

2. He suggests that my problems are not as

neg

bad as the problems most other people

have.

3. He takes time to think about the things

pos

I tell him before answering me.

4. He changes topics when I ask him

something about himself.

5. If something is bothering me he lets me

talk about it and get it off my chest.

6. He asks many questions that are not

related to the problem(s) I am seeing

him for.

7. He tells me that he is encouraged or

pleased by the way I am dealing with

things.

8. He indicates that I have certain thoughts

neg

or feelings that are wrong or bad. 
Table 2 (Continued)

Item

Valence

9. When he tells me his view of me, he

balances the positives with the negatives.

10. He tells me things about himself so that

pos

I can get to know him better.

11. He asks me to remind him of things I've

neg already told him.

12. He asks for my opinion or feelings about

pos things he says.

13. He indicates that he respects me despite pos the problems I have.

14. He disagrees with me about what we should neg talk about.

15. He talks so much that I don't get a neg chance to say as much as I would like.

16. He indicates that I should ask questions pos if what he says is not clear.

17. He tells me that I am wrong or does not neg approve of certain things I say or do.

18. He indicates that he is hopeful I will pos get better. 
Table 2 (Continued)

19. He uses his sense of humor to lighten

pos things up a bit.

20. His voice is harsh.

neg

21. His words come out with pauses and neg hesitations.

22. He indicates that "we" will work pos together to try to solve my problems.

23. He states back to me things that I tell pos him in order to be sure he understands me.

24. He makes "small talk" about every day pos things.

25. His voice is pleasant. pos

26. He gives me wrong information. neg

27. He nods his head as a way of agreeing pos with me when I'm talking.

28. He indicates that my concerns or problems neg are silly.

29. He misstates things that I have said. neg

30. He gives me advice or suggestions about pos how to deal with my problems. 
Table 2 (Continued)

31. He says that what we talk about will be kept private.

32. He tells me his view of my problems and pos what it will take for me to feel better.

33. He uses words top big for me to neg understand.

34. He gives me the same advice even though neg it hasn't worked for me in the past.

35. He talks too rapidly for me to easily neg follow what he is saying.

36. He talks about his own experiences if pos they relate to what I'm going through.

37. He makes decisions that affect me neg without asking for my input.

38. He indicates that for therapy to work, pos we need to trust each other.

39. He moves some part of his body, like his neg hands or feet, a lot.

40. He says something encouraging to me when pos we part. 
Table 2 (Continued)

I tem

Valence

41. He'll tell me that he thinks I may get pos hurt by something that I am planning to do.

42. He interrupts me without explaining or neg apologizing.

43. He forgets things that I tell him.

neg

44. He agrees with just about everything I

pos say.

45. He indicates that he (or somebody) will pos be available if I really need to talk.

46. He leans slightly forward in his chair. pos

47. He is amused by things about me that I neg don't find funny.

48. He looks at his watch. neg

49. He finishes my sentences before I can neg say what I am thinking.

50. He is easily distracted and loses his neg train of thought.

51. He indicates that for therapy to work, pos it is important that I trust him. 52. He is quiet and hardly says anything. 
Table 2 (Continued)

I tem

Valence

53. He looks at different parts of my body,

neg other than my eyes.

54. He says that he will be able to help me pos with my problems.

55. He gives long and drawn out answers to neg even the simplest questions.

56. When he first sees me he smiles and is pos warm.

57. When he gives me advice he will say "why pos don't you try..." or "have you thought about..." rather than just telling me to do something.

58. He holds his eye contact when talking pos to me.

59. He touches me on the shoulder, arm, or pos other such place.

60. He suggests that the best way of doing neg things is his way.

61. He gives me information and tells me pos what he knows about the problems I have. 
Table 2 (Continued)

62. If he is late or there is an

interruption he will apologize.

63. He appears comfortable and relaxed.

pos

64. He indicates that it is 0.K. to say

pos

whatever I happen to be feeling or

thinking.

65. He looks away when certain topics come up.

66. He shakes my hand when greeting or parting.

67. He remembers and brings up things that I have talked about before.

68. He tells me what I should do if I need pos help in an emergency.

69. The expression on his face is serious and rarely changes.

70. He asks me how things are going for me pos in certain areas of my life, even if they are not related to the problems that brought me to him.

71. He is quick to smile. 
Table 2 (Continued)

Item

Valence

72. He hurries our conversation along as if neg

he were impatient with me.

73. He explains things to me in an overly

neg simple way.

74. He talks about other patients.

neg

75. He raises his voice.

neg

Note. "Pos" denotes that the item was thought to increase trustworthiness; "neg" denotes that the item was thought to decrease trustworthiness. 


\section{STAGE II: SCALE REFINEMENT}

Method

overview

The goal of the scale refinement stage was to separate items highly relevant to therapist trustworthiness from less relevant items, thereby creating a scale of high construct fidelity and of reasonable length. Scale refinement was accomplished through a several stage process of item rating and evaluation. Item ratings were conducted by having a large sample of psychotherapy consumers evaluate the items with regard to therapist trustworthiness. Because the value of the scale is related, in part, to its potential utility for providing prescriptive feedback to therapist trainees, an assessment by clinical educators of the "trainability" of each item also was conducted.

Item Ratings by Client Judges

subjects. Subjects were 65 adults who were recruited from several different sources, including an outpatient psychiatry clinic associated with a university-based hospital ( $\underline{n}=21)$, a community mental health center $(\underline{n}=11)$, an independent private practice $(\underline{n}=5)$, and from meetings of several community-based support groups catering to individuals with mental health interests or needs $(\underline{n}=28)$.

All subjects were either currently in some form of outpatient mental health treatment $(\underline{n}=37)$ or had in the past received outpatient mental health treatment $(\underline{n}=28)$. 
Demographic information and other characteristics of these subjects can be found in Table 3 .

Subjects from each of the service provision sites were recruited for participation by therapists in those settings. At the conclusion of a regularly scheduled session, therapists invited clients to participate in a confidential research study concerning therapy relationships. Subjects from community sources were recruited for participation through a personal appeal by the author during one of the scheduled meetings of the respective support group.

Rating Procedure. Subjects were provided a consent form, a data sheet for providing demographic and treatment history information, and the randomly ordered item list with instructions for making ratings. (See Appendix B for the rating materials and instructions provided to subjects.)

Two questions were asked of raters with respect to each item: (a) If a therapist emitted the behavior described in an item, would it increase, decrease, or otherwise not influence the trustworthiness of that therapist? and, (b) If the item is related to increasing or decreasing a therapist's trustworthiness, how important a determinant of trustworthiness is the described behavior? Subjects rated whether each item increased, decreased, or was not related to trustworthiness, by circling $(+),(-)$, or $(\mathrm{n} / \mathrm{a})$, respectively. Ratings of each item's importance followed the initial relevance judgment. Subjects rated only those items determined to be trust- 
Table 3

Demographic and other Characteristics of subjects who served as Item Raters

Characteristic

N $\quad$ Percent

Mean Age

40.6 years

Sex

Female

42

64.6

Male

23

35.4

Race

Caucasian

65

100

other

0

0

Marital status

single

36

55.4

Married

29

44.6

Education status

Some high school or less

1

1.6

High school degree

21

32.3

College or college degree

43

66.1 
Table 3 (Continued)

Characteristic

$\underline{\mathrm{N}}$

Percent

Yearly Income

Under $\$ 10,000$

10

15.4

$\$ 10,001-20,000$

8

12.3

$\$ 20,001-30,000$

19

29.2

$\$ 30,001-40,000$

10

15. 4

$\$ 40,001-50,000$

3

4. 6

Over $\$ 50,000$

15

23.1

Employment status

Full-time employed

58.5

Part-time employed

7

10.8

Unemployed

16

24.6

student

4

6.1

Therapy status

Current client

37

56.9

Former client

28

43.1

Previous Psychiatric Hospitalization

Yes

29.3

No

70.7 
increasing $(+)$ or trust-decreasing $(-)$ using an 8 -point Likerttype scale with $1=$ somewhat 1 mportant and $8=$ extremely important in increasing (or decreasing) a therapist's trustworthiness. The adjective somewhat important was used to qualify the lowest anchor because it was assumed that an anchor indicating the lack of importance (e.g., "not at all important") was equivalent to a not related ( $\mathrm{n} / \mathrm{a})$ initial relevance judgment. Subjects were asked to rate the behaviors as they applied to therapists "in general" rather than to rate their own therapist (if they were currently in treatment). subjects returned the rated items to the investigator via a self-addressed and stamped envelope.

\section{Ratings by Clinical Educators}

Subjects. Four experienced clinical educators (one female and three males) representing the fields of social work, psychiatry, and clinical psychology were asked to judge whether the therapist behaviors depicted in each item were amenable to training. Judge 1 , the Director of social work at a private university-affiliated psychiatric hospital, was a licensed social worker (MSW, ACSW) who had 23 years of clinical service provision and had been actively involved in trainee education and supervision for 17 years. She described her orientation as "dynamic and family systems." Judge 2, a PhD level "cognitivebehavioral" oriented clinical psychologist had supervised and trained psychology interns for 11 years. He served as Director of Research at the same psychiatric hospital as Judge 1 . Judge 
3 was a "biopsychosocial cognitive-behavioral" oriented psychiatrist who served as the Assistant Psychiatrist-in-Chief at a university-based general hospital. He was also the codeveloper and coordinator of a two course medical school curriculum designed for training students fundamental interviewing competencies. He had actively supervised psychiatry trainees for 8 years. Judge 4 , another psychiatrist, was Director of Rehabilitation at a second university-affiliated teaching hospital. For 16 years he had developed and researched methods for teaching family therapy skills to a multidisciplinary student population. He characterized his orientation as "dynamic and systems" focused.

Rating procedure. The judges were provided the 75-item list and asked simply to indicate "yes" or "no" regarding their perceived ability to instruct a trainee to reliably emit (if trust-increasing) or to reliably not emit (if trust-decreasing) each of the described behaviors. The instructions provided to judges can be found in Appendix $C$.

Results

A two-step criterion initially was used to eliminate items from the pool. The percentage of respondents rating each item as trust-increasing, trust-decreasing, or unrelated to trustworthiness was calculated. Items that were not endorsed by at least $75 \%$ of respondents as either trust-increasing or trust-decreasing automatically were eliminated from the pool. This criterion facilitated the detection and deletion of 
ambiguous items. Twenty-three items were eliminated on the basis of this criterion. The percentage agreement on the judgments for each item can be found in Appendix D.

For each of the remaining 52 items the mean "importance" rating was calculated. Items in this pool of consensually determined relevant descriptors were eliminated if they did not achieve a mean importance rating of at least 6.0 out of 8.0 . This second criterion facilitated the detection and deletion of items that were not judged to be at least moderately to strongly associated with therapist trustworthiness. This second criterion caused an additional 28 items to be eliminated, leaving 24 items from the original pool. The mean rating for each item can be found in Appendix E.

The final criterion on which item elimination was based concerned the evaluation of each item's prescriptive utility for training. An agreement index of $75 \%$, calculated on the basis of ratings by the clinical educator judges (i.e. positive endorsement by 3 out of 4 judges), was set as the lowest acceptable limit for regarding an item as "trainable." Seven items in the original 75 item pool failed to meet this criterion. However, each item falling below the $75 \%$ agreement cutoff also failed to achieve a mean importance rating of 6.0 or greater. Therefore, no items were eliminated solely on the basis of judgments by the clinical educators. However, informal and unsolicited feedback provided independently from several of the judges regarding adverse clinical and/or ethical 
implications of one item was used to justify the elimination of that 1tem. Item 31 ("He says that what we talk about will be kept private") was eliminated because two judges noted that the confidentiality restriction implied by this statement could be both unethical and illegal if followed (e.g., in cases of abuse, neglect, suicidality, etc.). The two judges agreed that they could instruct a trainee to emit that behavior, however, they would not because of the above concerns.

The author eliminated three additional items. Item 45 ("He indicates that he (or somebody) will be available if I really need to talk") was eliminated because it was appraised by the author and two judges to be redundant with Item 68 ("He tells me what I should do if I need help in an emergency"). Item 64 ("He indicates that it is $0 . \mathrm{K}$. to say whatever I happen to be feeling or thinking") was eliminated accidentally. Although the scale was not designed originally to be applicable to group therapist evaluation, Item 74 ("He talks about other patients") was eliminated to make the measure more amenable for this purpose. This item elimination and scale refinement process created a 20-item measure. Fourteen of these items contained descriptions of behaviors that facilitated trustworthiness, whereas six items contained descriptions of behaviors that decreased trustworthiness.

Several different rating formats were considered for use with the scale, including frequency, appropriateness, and satisfaction indices as the underlying measurement dimension. 
A 6-point fully anchored ordinal scale assessing the extent of respondents' agreement/disagreement that the item was descriptive of the rated therapist was chosen as the format. scale anchors ranged from completely agree (1) to completely disagree (6). Because of the heterogeneity of scale items, this measurement dimension was felt to be the most logical, the least complex, and provided the best fit.
A set of instructions was created explaining how the measure was to be used in rating therapists. Instructions were written specifically to encourage the respondent to make ratings based on observations of what he or she "has observed [the] therapist to say and do" in the context of treatment sessions. The scale was titled: Therapist Behavior Rating scale (TBRS). The TBRS can be found in Appendix F. 


\section{STAGE III: PRELIMINARY PSYCHOMETRIC EVALUATION}

\section{Method}

\section{Overview}

The goal of the psychometric evaluation of the TBRS was to conduct a preliminary assessment of several reliability and validity properties of the scale. This was accomplished by having a sample of psychotherapy consumers rate their clinicians using the present scale and several other measures. Subjects

Subjects consisted of 138 therapist-client dyads engaged in outpatient therapy in several mental health service settings, including an outpatient clinic of a universityaffiliated private psychiatric hospital $(\underline{\mathrm{n}}=81)$, private practice offices $(\underline{n}=44)$, and the psychiatry clinic of a university-based general hospital ( $\underline{n}=13$ ). The 25 clinicians (13 females, 12 males) represented a variety of professional affiliations, theoretical orientations, and levels of experience. They had a mean age of 36.4 years and reported on the average 5.5 years of post-training professional experience. Demographic, professional, and other characteristics of the clinician sample are presented in Table 4.

The client sample consisted of 96 females and 42 males with a mean age of 40 years. Previous outpatient mental health treatment was reported by $57.8 \%$ of the clients and $22.7 \%$ reported at least one previous psychiatric hospitalization. The mean number of sessions for each client at the time of 
Table 4

Demographic and Professional Characteristics of Therapists

Characteristic

$\underline{\text { N }}$

percent

Mean Age

36.39 years $^{2}$

Sex

Female

Male

Education

PhD

MSW

MD

MA

orientation

Psychoanalytic/Dynamic

Cognitive-Behavioral

other
13

12

14

7

1

3

5

15

5

7
52.0

48.0
4

(1)

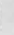
12.0

56.0

28.0

4. 0

20.0

60.0

20.0

Note. ${ }^{1}$ Age range $=28-51$ years. 
participation was $28.2(\underline{S D}=38.79 ;$ range $=3-300 ;$ mode $=4.0$; median $=13.0)$. Demographic and diagnostic characteristics of participating clients are shown in Table 5.

\section{Procedure}

Therapists announced to clients in their current caseload that they were participating in a study involving therapy relationships and invited them to participate. They were asked to recruit clients representing varying treatment lengths, relationship qualities, and diagnostic characteristics.

Therapists were asked to recruit between 5 and 15 clients to ensure a sufficient number of subjects for analysis. Further, the upper limit was established to prevent data from any one clinician from overly influencing the results. The therapists were given the discretion to not recruit clients whom they felt would be affected adversely by the procedure (i.e., evaluating their therapist). This consideration, while potentially biasing the subject sample, was mandated by several of the human subject protection committees who reviewed this project. Clients were informed by their therapists that their names would not appear on any of the forms and that a number coding system for therapists' and clients' ratings would keep all participants' data confidential. Clients were explicitly informed that their ratings would be strictly confidential and would not be shared with their therapists. Interested clients were provided a packet containing a consent form and rating materials with the instruction to complete the forms at the 
Table 5

Demographic and other Characteristics of Clients

Characteristic

$\underline{\mathrm{N}}$

Percent

Mean Age

40.01 years $^{1}$

$\operatorname{sex}$

Female

96

69.5

Male

42

30.5

Race

Caucasian

124

89.8

other

14

10.2

Marital status

Single

50.0

Married

69

50.0

Education status

some high school or less

$4 \cdot 3$

High school degree

30

21.8

College or college degree

102

73.9

Employment status

Ful1-time job

84

60.9

Part-time job

24

17.4

Unemployed

21

15.2

student

9

6.5 
Table 5 (Continued)

Characteristic

$\underline{\mathrm{N}}$

percent

Yearly Income

Under $\$ 10,000$

12. 3

$\$ 10,001-20,000$

27

19.6

$\$ 20,001-30,000$

23

16.7

$\$ 30,001-40,000$

25

18.1

$\$ 40,001-50,000$

17

12.3

over $\$ 50,000$

29

21.0

DSM-III-R Axis I Diagnosis

Mood Disorder

55

39.9

Anxiety Disorder

18

13.0

Adjustment Disorder

18

13. 0

Psychological Factors

7

5. 1

Substance Use

20

14.4

Eating Disorder

7

5.1

$\mathrm{V}$ Code

3

2.2

None Listed

7. 3

DSM-III-R Axis II Diagnosis

Cluster A

4

2.9

Cluster B

16

11.6

Cluster C

12

8.7

None Listed

106

76.8 
Table 5 (Continued)

Characteristic

$\underline{\mathrm{N}}$

Percent

outpatient Therapy History

Previous Treatment ${ }^{2}$

80

58.0

No Previous Treatment

58

42.0

Previous Psychiatric Hospitalization

Yes

23.2

No

106

76.8

Site

Private Psychiatric Hospital

81

58.7

Private Practice

44

31.9

General Hospital Clinic

13

$9 \cdot 4$

Mean Number of Treatment Sessions

at Time of study Participation

$28 \cdot 2^{3}$

Note. ${ }^{2} \underline{\text { SD }}=13.73$, range $=19-77$ years.

${ }^{2}$ Mean of previous times $=2.2, \underline{S D}=1.5$, range $=1-8$.

$\underline{S D}=38.79$, range $=3-300$, mode $=4$, median $=13$. 
conclusion of the session. Included in the packet was a demographic form, the TBRS, the Counselor Rating Form-Short Version (CRF-S; Corrigan \& Schmidt, 1983) and four 6-point fully anchored Likert-type scales assessing (a) problem severity, (b) amount of improvement in presenting problems, (c) degree of trust in the therapist, and (d) degree of openness and sharing in treatment sessions. (See Appendix F for the TBRS; see Appendix G for other rating materials.)

Upon completion of the ratings, clients sealed the materials in an envelope and provided them to a receptionist. Clients who could not complete the ratings on-site immediately after the session took the measures home and returned them to the investigator in a stamped self-addressed envelope. All clients recruited by private practitioners took the materials home to complete and returned them to the investigator by mail. Therapists provided information regarding the duration of treatment and clients' DSM-III-R Axis I and Axis II diagnoses, if applicable. Therapists also provided four individual item Likert-type ratings (6-point fully anchored scales) on variables corresponding to the ratings provided by patients: (a) current severity of the client's presenting problems, (b) amount of improvement in presenting problems, (c) degree that the client trusts him/her, and (d) the degree to which the client is open and sharing in sessions. Materials completed by therapists are found in Appendix $\mathrm{H}$.

Seven therapists were asked to readminister the TBRS to a 
subset of 27 recruited clients at the session following the first administration of rating scale materials. This procedure allowed for an examination of the test-retest reliability of the measure.

\section{Results}

\section{General scale Characteristics}

The 6-point Likert-type rating dimension was kept consistent for both positive and negative items on the TBRS (i.e., each item was anchored by (1) completely agree to (6) completely disagree). Positive items were reverse keyed during scoring such that higher total ratings on the scale reflected higher endorsement by clients of the extent to which therapists behaved in a trustworthy manner. Total scores on the 20-item scale, therefore, could range from a low of 20 to a high of 120.

The mean total score for the TBRS was 106.82 ( $\underline{\mathrm{SD}}=9.70$; range $=75-120)$. Table 6 contains descriptive statistics for TBRS ratings made on each of the 25 therapists. Total TBRS scores across therapists ranged from 75 to 120 . Score ranges and standard deviations for individual therapists generally showed considerable variability.

Item means, variances, and corrected item-total

correlations for the TBRS can be found in Table 7 . Seventeen (85\%) of the items had mean values greater than 5.0 (out of a possible 6.0 ). Items 10,12 , and 15 were the only items with mean values which fell below this point, at 
Table 6

Descriptive Statistics for TBRS Scores by Individual Therapist

\begin{tabular}{|c|c|c|c|c|}
\hline Therapist & $\underline{M}$ & $\underline{S D}$ & Range & $\mathrm{N}$ \\
\hline 1 & 93.00 & 3.56 & $89-96$ & 4 \\
\hline 2 & 107.80 & 9.09 & $95-120$ & 10 \\
\hline 3 & 110.67 & 9.45 & $100-118$ & 4 \\
\hline 4 & 107.67 & 6.74 & $102-120$ & 6 \\
\hline 5 & 99.43 & 11.00 & $80-111$ & 9 \\
\hline 6 & 106.67 & 7.77 & $91-117$ & 12 \\
\hline 7 & 111.71 & 8.38 & $95-118$ & 9 \\
\hline 8 & 95.12 & 13.28 & $75-113$ & 8 \\
\hline 9 & 107.64 & 7.40 & $91-116$ & 13 \\
\hline 10 & 112.50 & 2.89 & $109-116$ & 4 \\
\hline 11 & 107.40 & 6.73 & $96-114$ & 5 \\
\hline 12 & 111.86 & 3.89 & $105-115$ & 8 \\
\hline 13 & 114.75 & 4.35 & $109-119$ & 4 \\
\hline 14 & 96.00 & ---- & ---- & 1 \\
\hline 15 & 105.33 & 6.66 & $98-111$ & 4 \\
\hline 16 & 112.60 & 6.58 & $102-120$ & 5 \\
\hline 17 & 106.38 & 5.40 & $100-115$ & 9 \\
\hline 18 & 113.67 & 6.11 & $107-119$ & 4 \\
\hline 19 & 99.00 & --- & ---- & 1 \\
\hline 20 & 107.50 & 12.02 & $99-116$ & 2 \\
\hline
\end{tabular}


Table 6 (Continued)

\begin{tabular}{|c|c|c|c|c|}
\hline Therapist & $\underline{M}$ & $\underline{\mathrm{SD}}$ & Range & $\mathrm{N}$ \\
\hline 21 & 116.00 & 3.16 & $113-120$ & 6 \\
\hline 22 & 98.33 & 4.04 & $94-102$ & 5 \\
\hline 23 & 108.33 & 7.23 & $100-113$ & 3 \\
\hline 24 & 113.00 & ---- & ---- & 1 \\
\hline 25 & 120.00 & ---- & ---- & 1 \\
\hline
\end{tabular}

Note. The mean number of client evaluations obtained for each therapist was 5.52 ( $r$ ange $=1-13$ ). 
$4.85,4.21$, and 4.87 , respectively. The standard deviation for $15(75 \%)$ of the items was less than 1.0 .

Scale Reliability

The internal consistency of the scale was estimated by several statistics. Cronbach's alpha was .87, the spearman Brown split-half reliability formula yielded a correlation of .81 , and the Guttman split-half formula yielded a coefficient of .80 . The individual item-total correlations, which are presented in Table 7 show moderate correlations for 19 of the 20 items. Seventeen of the items have coefficients above .40. The mean item-total correlation was .46 with a range of .26 to 60. The test-retest reliability of the TBRS, calculated on 27 clients' ratings of 7 therapists, resulted in a Pearson Product-Moment correlation coefficient of $.77, \underline{p}<.001$. The test-retest interval averaged 10.3 days (range $=5-14$ days) .

\section{Validity Analyses}

Several indices of the present measure's validity were evaluated by examining the relation of total scores on the TBRS to various client- and therapist-rated variables. Presented in Table 8 are the correlations of the TBRS scores with client and therapist ratings. Evidence for convergent validity is indicated by the association between the TBRS and clients' rating of trust in their therapist. There was a moderate positive association found between these two variables $(\underline{r}=.45, \underline{p}<.001)$. However, there was no corresponding significant association found between TBRS scores and the 
Table 7

Item Means, Standard Deviations, and Corrected Item-total Correlations

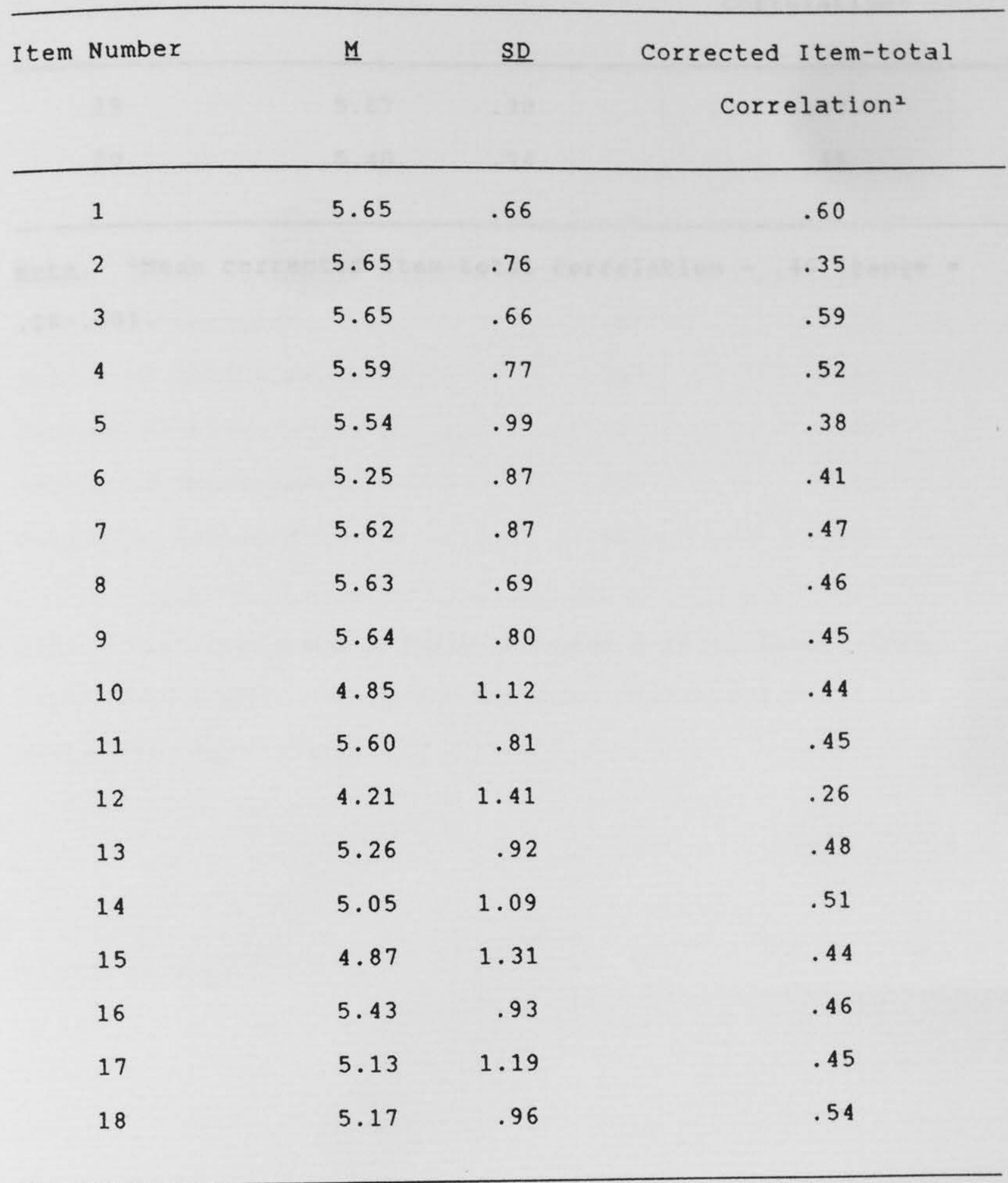


Table 7 (Continued)

$\begin{array}{ccc}\text { Item Number } \quad \underline{S D} \quad \text { Corrected Item-total } \\ & \text { Correlation }{ }^{2}\end{array}$

\begin{tabular}{lrrr}
19 & 5.67 & .70 & .47 \\
20 & 5.40 & .74 & .45 \\
\hline
\end{tabular}

Note. ${ }^{2}$ Mean corrected item-total correlation $=.46$ ( range $=$ $.26-.60)$. 
Table 8

pearson Correlation Coefficients of Total TBRS Scores with

Patient status Ratings and Therapy Process Ratings From Client and Therapist Perspectives

Perspective

Client

Theraplst

Trust in Therapist

$.45^{2}$

.17

Degree of Self Disclosure

$.32^{2}$

.13

Current Problem Severity

$-.01$

$-.02$

Amount of Improvement

$.29^{2}$

.18

Counselor Rating Form-S

$.63^{2}$

Note. Each scale was a fully anchored 6-point Likert-type scale with higher scores representing higher values of the variable. ${ }^{2} \mathrm{p}<.001$. 
therapists' ratings of their clients' degree of trust in them. The association between the TBRS and client-rated selfdisclosure was calculated to provide one index of construct validity. The association between these two variables was moderate $(\underline{r}=.32, \underline{p}<.001)$. Second, a positive association of similar magnitude $(\underline{\underline{r}}=.29, \underline{\mathrm{p}}<.001)$ between the TBRS and client-rated improvement provided an additional piece of evidence bearing on construct validity. Neither of the two corresponding ratings provided by therapists for these variables were significantly related to TBRS scores. Further evidence related to the construct validity of the measure is suggested by the strong positive correlation of the TBRS with the CRF-S $(\underline{\underline{r}}=.63, \underline{\mathrm{p}}<.001)$. The CRF-S is best considered to be a global measure of a client's degree of 1 iking and satisfaction with the therapist (Ponterotto \& Furlong, 1985).

The absence of significant associations between TBRS scores and several variables lacking clear conceptual ties to trustworthiness is seen as indirect support for the discriminant validity of the TBRs. For example, clients' current level of self-rated symptomatic distress was unrelated to TBRS scores $(\underline{\underline{z}}=-.01, \mathrm{n} . \mathrm{s}$.$) . Additionally, there were no$ significant correlations between TBRS ratings and treatment duration $(\underline{r}=.10, n . s$.$) , client age (\underline{r}=.11$, n.s.), educational level $(\underline{r}=.06$, n.s. $)$, income $(\underline{r}=-.11, \mathrm{n} . \mathrm{s}$.$) or$ therapist age $(\underline{r}=-.01, n . s$.$) .$ 


\section{Multiple Regression}

A multiple regression analysis was conducted to examine predictors of client trust ratings in an attempt to provide further validational support for the TBRS. The contribution to predicting client ratings of trust in their therapist by the following ten variables was examined: (a) TBRs total score, (b) duration of treatment relationship, (c) years of therapist experience, (d) client-rated self-disclosure, (e) client-rated improvement, (f) client-rated problem severity, (g) therapistrated trust, (h) therapist-rated self-disclosure, (1) therapist -rated improvement, and ( $j)$ therapist-rated problem severity. Variables were entered into the regression equation simultaneously.

Using this set of variables in the prediction equation, an $\underline{R}$ of .73 was obtained for the regression model, $\underline{\mathbf{F}}(10,127)=$ $13.58, \underline{\mathrm{p}}<.001$. The 10 variables thus accounted for $52.1 \%$ of the variance in client ratings of trust. Examination of the standardized beta coefficients revealed that three variables made significant contributions to the overall multiple $R$ : Client-rated self-disclosure (Beta $=.46, \underline{p}<.001$ ), TBRS total score (Beta $=.26, \mathrm{p}<.002)$, and client-rated improvement $($ Beta $=.20, \underline{\mathrm{p}}<.05)$.

\section{Dimensionality study}

An exploratory-descriptive factor analysis was conducted to examine the underlying structure of ratings on the TBRS. The data were submitted to a principal components analysis 
using the Kaiser criterion (i.e., eigenvalues $>$ or $=$ to 1.0 ) initially to select the number of factors. The statistical Package for the Social Sciences (SPSS/PC+ V3.0) was used to perform the analysis. A 5-factor solution resulted in which the factors explained $57.5 \%$ of the total varlance.

A varimax rotation was performed on the five factors. Examination of the resulting factor structure matrix revealed a solution that was highly ambiguous. Factors extracted later in the solution contained numerous items that had substantial loadings on at least several factors. Factor 4 and Factor 5 contained items of discordant content and were not easily interpretable. Factor 5 was a couplet factor. These latter two factors in this solution were thought to reflect error variance rather than substantative components. In light of these findings, Cattell's scree test was examined to clarify the decision regarding the number of factors. The plot of eigenvalues suggested that a 3 -factor solution was most appropriate for the data. The results of the varimax rotation of the 3-factor solution are presented in Table 9. The 3factor solution accounted for $46.1 \%$ of the total variance. As shown, a reasonably parsimonious factor structure was produced. The first factor contained eight items in which all but one were trust-facilitating responses. This factor was composed of items representing the therapist's interest, respect, concern, and focused attention towards the client. Factor loadings for this dimension ranged from .49 to .70 and 
accounted for $28.8 \%$ of the variance. This dimension was labeled: Positive Regard/Interest.

The second factor consisted entirely of negative, trustdecreasing items. The six items on this factor represented therapist errors or miscommunications, indifference, dominance, and impatience. Factor loadings for this dimension ranged from .36 to .75 and accounted for $9.7 \%$ of the variance. This dimension was labeled: Incompetence/Disrespect.

The third factor was composed of the remaining six trustfacilitating items. Item content of this dimension reflected therapist responses that were advising, instructive, informative and encouraging. Factor loadings for this dimension ranged from .55 to .70 and accounted for $7.6 \%$ of the variance. This dimension was labeled: Directive/structuring.

To examine the integrity of the factors, internal consistency reliability estimates were computed. The internal consistency reliability was moderate to high for the three factors: Factor I, standardized alpha $=.81$; Factor II, standardized alpha $=.75$; Factor III, standardized alpha $=.74$. These results suggest adequate psychometric integrity of the three TBRS factors. Overall, the factor analysis produced a reasonably parsimonious solution with respect to item content on the three factors and factor interpretability. (see Appendix I for Factor Labels, Items, and Item Loadings.) 
Table 9

Rotated Factor Loading Matrix for the TBRS Using the Varimax Method

\begin{tabular}{|c|c|c|c|c|}
\hline \multirow[b]{2}{*}{ Item } & \multicolumn{4}{|c|}{ Factor } \\
\hline & 1 & 2 & 3 & $\underline{h}^{2}$ \\
\hline TBRS 3 & .70 & .14 & .26 & .57 \\
\hline TBRS19 &.$\underline{68}$ & .20 & .00 & .51 \\
\hline TBRS 4 & .67 & .18 & .15 & .50 \\
\hline TBRS 20 &.$\underline{58}$ & .01 & .30 & .43 \\
\hline TBRS 8 &.$\underline{58}$ & .21 & .09 & .39 \\
\hline TBRS 6 &.$\underline{55}$ & .18 & .04 & .34 \\
\hline TBRS 17 &.$\underline{50}$ & .00 & .37 & .39 \\
\hline TBRS1 & .49 & .36 & .29 & .46 \\
\hline TBRS 11 & .13 &.$\underline{75}$ & .10 & .59 \\
\hline TBRS 7 & .03 &.$\underline{75}$ & .11 & .58 \\
\hline TBRS 5 & .13 & .70 & .02 & .51 \\
\hline TBRS9 & .18 & .68 & .13 & .51 \\
\hline TBRS16 & .41 & $\cdot \underline{48}$ & .04 & .41 \\
\hline TBRS 2 & .21 & . 36 & .14 & .20 \\
\hline
\end{tabular}


Table 9 (Continued)

\section{Factor}

Item

1

2

3

$h^{2}$

\begin{tabular}{lcccc}
\hline TBRS12 & -.18 & .12 &.$\underline{70}$ & .54 \\
TBRS14 & .23 & .07 &.$\underline{69}$ & .54 \\
TBRS18 & .28 & .20 &.$\underline{59}$ & .47 \\
TBRS13 & .36 & -.05 &.$\underline{58}$ & .47 \\
TBRS15 & .27 & .05 &.$\underline{58}$ & .41 \\
TBRS10 & .07 & .27 &.$\underline{55}$ & .39 \\
Eigenvalue & & & & \\
Percent of Variance & 28.8 & 9.7 & 7.6 & \\
\hline
\end{tabular}

Note. The highest factor loading on each factor is underlined. The variance accounted for by the four factors $=46.1 \% ; \underline{h}^{2}$ indicates the communality of each item. 
Discussion

The purpose of the present study was to develop a psychometrically sound and useful rating scale to measure a set of therapist behaviors that contribute to client-perceived relational trust. Scores derived from the Trustworthiness Behavior Rating Scale (TBRS) reflect the degree to which therapists are observed by their clients to respond and interact in ways that affect their perceived trustworthiness. scale items cover a varlety of trust-facilitating and trustdecreasing responses that pertain to the content of therapist communication and/or the manner in which a therapist relates to a client. The content validity of the measure was enhanced by deriving items using observations and evaluative ratings provided by psychotherapy consumers.

Data collected from a clinical sample of therapist-client dyads engaged in outpatient treatment provided reasonable support for the preliminary validation of the TBRS. overall scores on the TBRS obtained for the entire sample of therapists showed satisfactory variance and range. Therapists who were evaluated by at least several clients generally elicited ratings from those clients that varled considerably. The broad distribution of scores found for these therapists indicated that the measure reflects, and is sensitive to, the divergent perceptions that various clients may form of the same therapist. Further, this result provides indirect and partial evidence that clients' use of the scale was not overly 
influenced by a systematic response bias favoring the clinician. Some range restriction and positive skewness for a number of individual scale items, however, was found. Internal consistency and temporal stability coefficients provided strong evidence for two important indices of the scale's reliability.

The correlations between the TBRS and client-completed measures of trust, self-disclosure, treatment outcome (i.e., gains in treatment at the time of evaluation), and a commonly used measure of positive therapist characteristics (Counselor Rating Form-S) provide favorable estimates of both the convergent and construct validity of the scale. For instance, the association between TBRS scores and ratings of trust suggests that the more clients observe their therapists to respond in a trustworthy manner, the higher the level of trust they have in their therapists. This finding conforms to a widely held hypothesis regarding trust in the therapeutic relationship, namely, that certain behavioral cues and therapist-offered events influence clients' perceptions that therapists can be trusted (e.g., Cormier \& Cormier, 1985). Or, as Fong and Cox (1983) suggested, "observable instances of trustworthiness" from the therapist form the basis for clients' development of trust (p. 163).

A therapist's ability to elicit perceptions of trustworthiness is thought to influence a patient's participation in, and benefit from, treatment (e.g., Kanfer \& Goldstein, 1975). The positive associations between the TBRS 
and self-disclosure and improvement variables support the view that trustworthy behaviors may, indeed, have specific implications for the treatment process. The association between TBRS scores and self-disclosure indicates that the more therapists are viewed as behaving in a trustworthy manner, the greater the degree to which clients view themselves as being more self-disclosing. The positive correlation between TBRS scores and self-rated improvement supports the view that treatment gains are facilitated, in some manner, by therapist behaviors indicative of trustworthiness.

The most elementary representation of the above relationships would hold that various therapist behaviors promote clients' perceptions of trustworthiness which establish the context for client-self disclosure. Self-disclosure, in turn, could provide some direct benefit for the patient while also providing the therapist with important material with which to work and aid the client in improving his/her situation. Consistent with such a representation is the fact that the association between the level of cllent trust and TBRS ratings exceeded the association between client self-disclosure and TBRS ratings. This pattern makes sense because the measure, by design, has a more direct theoretical link to trust than to self-disclosure.

Additional validational support was provided by the results of a multiple regression analysis which revealed that total TBRS score, as one of ten independent variables entered 
into the regression equation, was one of only three variables that made a significant contribution to predicting client ratings of therapist trust.

Some evidence of discriminant validity was suggested by the absence of significant associations between the TBRS and several variables lacking a clear conceptual relationship to trustworthiness. These variables included problem severity, treatment duration, and several primary demographic characteristics of both clients and therapists.

An exploratory principal-components analysis produced a reasonably interpretable factor structure consisting of three distinct dimensions accounting for $46.1 \%$ of the variance in TBRS ratings. The three rotated factors were descriptive of therapist: (a) positive/regard and interest, (b) incompetence/ disrespect, and (c) directive/structuring responses. The positive/regard and interest factor was the most prominent dimension of the three, accounting for approximately three and four times more variance than the second and third factors, respectively. This dimension taps responses reflective of "basic communication skills" often considered to be the foundation of the helping professional's repertoire (e.g., Egan, 1986). The incompetence/disrespect factor consisted entirely of responses that adversely affected perceptions of trustworthiness, such as therapist statements that were erroneous or critical, or responses that were otherwise lacking in sensitivity and understanding. The final dimension, 
directive/structuring, involved therapist responses that served to orient and advise the client regarding various aspects of the treatment process. These items also reflect a fairly high level of activity and contribution to treatment by the therapist. Of note, the modest respondent to item ratio in the analysis requires that the obtained factor structure be replicated in an independent sample to confirm the stability of the respective dimensions.

The data bearing on the validity estimates of the scale deserve some qualification. First, although the pattern of associations found between the TBRS and the measures of trust, self-disclosure, and treatment outcome were conceptually meaningful, the magnitudes of the validity correlations generally were modest. One factor that may have accounted for the modest size of these coefficients was the limited variability demonstrated for several of the measures. The two varlables whose relationships were of greatest interest from the standpoint of validity, that is, client-provided single Likert-type ratings of therapist trust and personal selfdisclosure, were the two measures with the least amount of variability (1.e., minimal standard deviations and ranges). Second, all of the evidence supporting the scale's validity was source-dependent, that is, only client-provided measures were significantly related to TBRS scores. Associations between TBRS ratings and therapist-provided measures were largely nonsignificant. The conservative explanation would be to credit 
method variance for these findings. On the other hand, therapy process researchers frequently have reported that the correspondence between therapist, client, (and external observer) evaluations of the same targets are more often dissimilar than similar (e.g., Caskey, Barker, \& Elliott, 1984; orlinsky \& Howard, 1986). Taking the position that therapist trustworthiness is best defined by giving greatest, if not exclusive weight to the phenomenological perspective of the client, it could be argued that those client-based correlations that proved to be statistically significant were the only ones of relevance.

These preliminary data on the psychometric properties of the TBRS suggest that it has promise as a potentially useful measure of therapist performance. From a training perspective, the TBRS addresses a void that exists among current approaches to skill assessment and development. That is, the paucity of behaviorally descriptive performance measures targeting relationship promotion skills (Alberts \& Edelstein, 1990). One of the first critical tests of this measure's utility for training and competency evaluation might involve comparing the performance (as measured vis-a-vis client-perceived assessment of trustworthiness) of novice trainees who are specifically instructed to emit sets of responses as depicted on the TBRS against trainees who do not receive such instruction.

As Schiffman (1983) has noted, many instructional models are wanting because "much therapist training deals with 
difficult to observe abstractions--'rapport, ' 'countertransference,' 'confrontation'" (p. 83). As a result, trainees typically are not provided with a means to monitor or gauge the impact of their behavior on the perceptions formed by their clients. Similarly, Rice and Greenberg (1984) have called for the development of strategies to aid in identifying and operationalizing "process markers" which denote critical relationship events occurring between client and therapist. Regarding one variant of process marker, Safran, Crocker, McMain, and Murray (1990) have suggested that the identification and resolution of therapist-induced "ruptures" in the treatment alliance can serve as potent change events in and of themselves. Additional research with the present instrument in training and clinical contexts is required, however, before it can be determined whether TBRS items are capable of facilitating constructive feedback or promoting therapeutic "metacommunication" of the type that safran et al. (1990) suggest.

There are a number of pertinent methodological limitations in this investigation. The therapists participating in the study were self-selected and therefore may not be representative of the general population of therapists. Because therapists were aware that the goal of the study entailed a form of performance evaluation, participation may have been influenced by the degree to which they felt that they were perceived by their clients to be performing 
satisfactorily. In fact, mean total TBRs ratings confirmed that the present sample of therapists were viewed overall as highly trustworthy. Also, given the fairly substantial average treatment length for therapist-client dyads at the time of measurement, it is apparent that most relationships were solidly established.

Regarding the client sample, the sex distribution and general demographic characteristics of participants were fairly consistent with those reported in large scale epidemiological surveys of outpatient psychotherapy consumers (e.g., Howard, Davidson, O'Mahoney, Orlinsky, \& Brown, 1989). However, this sample may have differed from clients in general in several other important respects. First, because therapists recruited clients for participation, they may have solicited subjects whom they felt would both comply with and not be adversely affected by the procedures. Clients meeting these criteria may experience trust and view the therapeutic relationship differently than clients who are judged to be less compliant and more vulnerable. Second, minority ethnic groups were not adequately represented in either the item development samples or the validation samples, further limiting the external validity of the results.

The rating criteria used to select items for inclusion in the scale may have resulted in the elimination of some potentially significant items. A number of items consensually judged to be highly "relevant" to trustworthiness were 
discarded because they fell slightly below the highly "important" rating criterion. An important consequence of this selection rule was the loss of a significant number of negatively valenced responses. Examples of several of these negative items include: "He is amused by things about me that I don't find funny" and "His voice is harsh." subsequently, fewer negative items were placed on the scale and the overall number of scale items was reduced as well. Less stringent criteria would have resulted in a scale of even greater heterogeneity and perhaps one capable of eliciting a more expansive range of ratings from respondents.

The issue of negative or deleterious aspects of certain therapist behaviors raises an important measurement consideration for the TBRS and therapist rating scales in general. It is probably safe to assume that a broad repertoire of trust facilitating responses (along with other basic interpersonal and clinical competencies), is more the rule rather than the exception among therapists. Strupp (1973) has referred to this basic therapist profile as an important component of the "average expectable atmosphere" of therapy. Therefore, given the normative or typical atmosphere of therapy (i.e., a trustworthy therapist), measures that are more sensitive to deviations in the "expectable" therapeutic climate might lead to a higher level of precision in the assessment and understanding of therapist competencies.

The measures used to establish the validity of the scale 
were themselves lacking in formal psychometric support. Reliance upon single-item rating scales was due to the economy and directness of such measures and to the lack of any empirically derived paper and pencil rating procedures for measuring the presence of trust or the degree of openness and self-disclosure. Notwithstanding the importance of measurements taken from the perspective of the client, more objective, behaviorally-based observational measures would have contributed significantly to the study. Behavior counts of clients' self-referencing "I-statements" as an index of selfdisclosure, for example, or quantifying other meaningful verbal responses using available coding schemes (e.g., Benjamin, 1974), represent several of these options.

with only preliminary evidence of the reliability and validity of the TBRS thus established, subsequent investigations will need to assess further the psychometric qualities of the measure. As mentioned above, validating the TBRS against measures that are more refined and more behavioral would represent a good starting point. of particular interest would be an examination of the relationship between the TBRS and some of the more recently developed patient-therapist alliance measures, such as the Working Alliance Inventory (WAI; Horvath \& Greenberg, 1989) or the Therapeutic Alliance Rating System (TARS; Marmar, wiess, \& Gaston, 1989). Such studies would aid in understanding how therapist trustworthiness relates to other elements of the treatment relationship that 
are tapped by alliance measures, such as the client's affective relationship to the therapist, or the cognitive congruence between client and therapist on the tasks and goals of therapy (Gaston, 1990).

Further validational studies and treatment process investigations with the TBRS could focus on examining the topology of trust development over time, or more importantly, identifying therapist behaviors that are differentially perceived as a function of the period or stage of treatment. Future applications of the TBRS should also involve client groups for whom the capacity to trust is often thought to be impaired, e.g., victims of sexual abuse, paranoid personality disorders, etc. The trustworthy therapist behaviors represented on the TBRS as developed and selected through more "generic" client sampling methods may have different representations for such individuals. Potentially, a different set of interpersonal tactics by therapists may be required to elicit perceptions of trustworthiness in these populations. In a more general sense, all the variance in accounting for trust in therapy relationships cannot be explained solely in terms of the behavior of the therapist. There remains for future study the identification of variables in the client's history and features of their current psychological status which interact with therapist factors to influence trust.

In summary, the TBRS demonstrated satisfactory psychometric qualities to warrant its continued evaluation and 
refinement as a potentially viable therapist performance rating scale. The results of this study add to previous efforts at specifying "microevents" which shape the therapist-client interactional process (Rice \& Greenberg, 1984), and which may constitute "common therapeutic factors" present among all treatment modalities (e.g., Greencavage \& Norcross, 1990). As Horvath and Greenberg (1989) noted, "One of the issues that [should continue] to be addressed... is the importance of developing and testing research instruments that are capable of isolating and quantifying the relationship variables that fit into [an] integrationist research context" (p. 231). 
References

Alberts, G., \& Edelstein, B. (1990). Therapist training: A critical review of skill training studies. Clinical Psychology Review, 10, 497-511.

Atkinson, D.R., \& Wampold, B.E. (1982). A comparison of the Counselor Rating Form and Counselor Effectiveness Rating scale. Counselor Education and Supervision, 22, 25-36. Baker, S.B., Johnson, E., Kopala, M., \& Strout, N.J. (1985). Test interpretation competence: A comparison of microskills and mental practice training. Counselor Education and supervision, 25, 31-43.

Baker, S.B., Scofield, M.E., Clayton, L.T., \& Munson, w.W. (1984). Microskills practice versus mental practice for competence in decision-making counseling. Journal of Counseling Psychology, 31, 104-107.

Baker, S.B., Scofield, M.E., Munson, W.W., \& Clayton, L.T. (1983). The effects of teaching basic counseling competencies through brief microskills versus mental practice training. Counselor Education and supervision, $\underline{23}, 71-82$.

Barak, A., \& LaCrosse, M.B. (1975). Multidimensional perception of counselor behavior. Journal of Counseling Psychology, 22, 471-476.

Barrett-Lennard, G.T. (1962). Dimensions of therapist response as causal factors in therapeutic change. Psychological Monographs, 76 (43, whole No. 562). 
Barrett, C.L., \& Wright, J.H. (1984). Therapist variables. In M. Hersen, L. Michelson, \& A.S. Bellack (Eds.), Issues in psychotherapy research (pp. 361-391). New York: Plenum. Beutler, L.E. (1991). Have all won and must all have prizes? Revisiting Luborsky et al.'s verdict. Journal of Consulting and Clinical Psychology, 59, 226-232. Benjamin, L.S. (1974). Structural analysis of social behavior. Psychological Review, 81, 392-425. Beutler, L.E., Crago, M., \& Arizmendi, T.G. (1986). Therapist variables in psychotherapy process and outcome. In S.L. Garfield \& A.E. Bergin (Eds.), Handbook of psychotherapy and behavior change (3rd ed., pp. 257-310). New York: wiley.

Beutler, L.E., Johnson, D.T., Neville, C.W., \& Workman, S.N. (1973). Some sources of variance in "accurate empathy" ratings. Journal of Consulting and Clinical Psychology, 40, 167-169.

Caskey, N., Barker, C., \& Elliott, R. (1984). Dual perspectives: Clients' and therapists' perceptions of therapist responses. British Journal of clinical Psychology, 23, 281-290. Collins, F., Foster, S., \& Berler, E. (1986). Clinical training issues for behavioral psychology. Professional Psychology: Research and Practice, 17, 301-307. Cormier, W.H., \& Cormier, L.S. (1985). Interviewing strategies for helpers (2nd Ed.). Monterey, CA: Brooks-Cole. 
Corrigan, J.D., \& Schmidt, L.D. (1983). Development and

validation of revisions in the Counselor Rating Form.

Journal of Counseling Psychology, 30, 64-75.

Dawes, R.V. (1987). Scale Construction. Journal of counseling

Psychology, 34, 481-489.

Egan, G. (1986). The skilled helper: A systematic approach to

effective helping. Monterey, CA: Brooks/Cole.

Fong, M.L., \& Cox, B.G. (1983). Trust as an underlying dynamic

in the counseling process: How clients test trust.

Personnel and Guidance Journal, 62, 162-166.

Ford, J.D. (1979). Research on training counselors and

clinicians. Review of Educational Research, 69, 87-130.

Frank, J. (1959). The dynamics of the patient-therapist

relationship: Determinants and effects of therapists '

influence. Psychiatry, 22, 17-39.

Frank, J. (1982). Therapeutic components shared by all

psychotherapies. In J.H. Harvey \& M.M. Parks (Eds.),

Psychotherapy research and behavior change (pp. 5-38).

Washington, DC: American Psychological Association.

Garfield, S.L. (1977). Research on the training of

professional psychotherapists. In A.S. Gurman \& A.M.

Razin (Eds.), Effective psychotherapy: $\underline{\text { A handbook }}$ of

research (pp. 3-83). New York: Pergamon.

Gaston, L. (1990). The concept of the alliance and its role in psychotherapy: Theoretical and empirical considerations. Psychotherapy, 27, 143-153. 
Gilbert, L.A., Lee, R.N., \& Chiddix, S. (1981). Influence of presenter's gender on students' evaluations of presenters discussing sex fairness in counseling: An analogue study. Journal of Counseling Psychology, 28, 258-264.

Goldstein, A.P. (1971). Psychotherapeutic attraction. New

York: Pergamon.

Goldstein, A.P., Heller, K., \& Sechrest, L.B. (1966).

Psychotherapy and the psychology of behavior change. New York: Wiley.

Grammatik III. (1988). Reference Software, Inc., San

Francisco, CA.

Greben, S.E. (1984). The re-establishment of trust through

psychotherapy. Canadian Journal of Psychiatry, 29, 350354 .

Greencavage, L.M. \& Norcross, J.C. (1990). Where are the

commonalities among the therapeutic common factors?

Professional Psychology: Research and Practice, 21, 372378.

Gurman, A.S. (1973). Instability of therapeutic conditions in psychotherapy. Journal of Counseling Psychology, 20, 1624 .

Gurman, A.S. (1977). The patient's perception of the therapeutic relationship. In A.S. Gurman \& A.M. Razin (Eds.), Effective psychotherapy: A handbook of research (pp. 503-543). New York: Pergamon. 
Heesacker, M., \& Heppner, P.P. (1983). Using real client perceptions to examine psychometric properties of the Counselor Rating Form. Journal of Counseling Psychology, 30, $180-187$.

Heppner, P.P. \& Dixon, D.N. (1981). A review of the interpersonal influence process in counseling. Personnel and Guidance Journal, 59, 542-550.

Hill, C.E. (1982). Counseling process research: Philosophical and methodological dilemmas. The Counseling Psychologist, $10,7-19$.

Hill, C.E., Charles, D., \& Reed, K. (1981). A longitudinal analysis of changes in counseling skills during doctoral training in counseling psychology. Journal of Counseling Psychology, 28, 428-436.

Hirschenberger, R. H., McGuire, P.S., \& Thomas, D.R. (1987). Criterion-referenced, competency-based training in behavior modification. In B.A. Edelstein \& E.S. Berler (Eds.), Evaluation and accountability in clinical training (pp. 299-329). New York: Plenum Press. Horvath, A.O., \& Greenberg, L. (1986). The development of the Working Alliance Inventory. In L.S. Greenberg \& W.M.

Pinsof (Eds.), The Psychotherapeutic process: A research handbook (pp. 529-556). New York: Guilford Press. Howard, K., Davidson, C., O'Mahoney, Orlinsky, D., \& Brown, M. (1989). Patterns of psychotherapy utilization. American Journal of Psychiatry, 146, 775-778. 
Jenkins, w.W. (1982). The development and evaluation of a scale to rate counselor interview competence. Dissertation Abstracts International, 43, 673A, (University Microfilms International No. DAB2-18,911). Johnson-George, C., \& Swap, w.C. (1982). Measurement of specific interpersonal trust: Construction and validation of a scale to assess trust in a specific other. Journal of Personality and Social Psychology, 43, 1306-1307. Kanfer, F.H. \& Goldstein, A.P. (Eds.). (1975). Helping people change: A textbook of methods. New York: Pergamon. Kaul, T.J., \& Schmidt, L.D. (1971). Dimensions of interviewer trustworthiness. Journal of Counseling Psychology, 18 , $542-548$ Lacrosse, M.B. (1977). Comparative perceptions of counselor behavior: A replication and extension. Journal of Counseling Psychology, 24, 464-471. Lacrosse, M.B., \& Barak, A. (1976). Differential perceptions of counselor behavior. Journal of Counseling psychology, 23, $170-172$.

Lambert, M.J. (1989). The individual therapist's contribution to psychotherapy process and outcome. Clinical psychology Review, $\underline{9}, 469-485$.

Lambert, M.J., \& Bergin, N.E. (1983). Therapist characteristics and their contribution to psychotherapy outcome. In C.E. Walker (Ed.), The handbook of clinical psychology (pp. 205-241). Homewood, IL: Dow Jones-Irwin. 
Lambert, M.J., Shapiro, D.A., \& Bergin, A.E. (1986). The effectiveness of psychotherapy. In S.L. Garfield \& A.E. Bergin (Eds.), Handbook of psychotherapy and behavior change (3rd ed., pp. 157-211). New York: Wiley. Lazelere, R.E., \& Huston, T.L. (1980). The Dyadic Trust scale: Toward understanding interpersonal trust in close relationships. Journal of Marriage and the Family, 42 , $595-604$

Luborsky, L., Singer, B., \& Luborsky, L. (1975). Comparative studies of psychotherapies: Is it true that "everyone has won and all must have prizes"? Archives of General Psychiatry, 32, 995-1008. Marmar, C.R., Weiss, D.S., \& Gaston, L. (1989). Towards the validation of the California Therapeutic Alliance Rating system. Journal of Consulting and Clinical Psychology, 57, 46-52.

Matarazzo, R.G. (1978). Research on the teaching and learning of psychotherapeutic skills. In S.L. Garfield \& A.E. Bergin (Eds.), Handbook of psychotherapy and behavior change (pp. 895-924). New York: Wiley. Mintz, J., \& Luborsky, L. (1971). Segments vs. whole sessions: Which is the better unit for psychotherapy research? Journal of Counseling Psychology, 36, 106-120. 
Morgan, R., Luborsky, L., \& Crits-Cristoph, P. (1982).

predicting the outcomes of psychotherapy by the Penn Helping Alliance Rating Method. Archives of General Psychlatry, 39, 397-402.

orlinsky, D.E., \& Howard, K.I. (1986). Process and outcome in psychotherapy. In S.L. Garfield \& A.E. Bergin (Eds.), Handbook of psychotherapy and behavior change: An empirical analysis ( $3 r d$ ed., pp. 311-381). New York: wiley.

Parloff, M.B., Waskow, I.E., \& Wolfe, B.E. (1978). Research on therapist variables in relation to process and outcome. In S.L. Garfield\& A.E. Bergin (Eds.), Handbook of psychotherapy and behavior change: An empirical analysis (2nd ed., pp. 223-282). New York: Wiley. Ponterotto, J.G., \& Furlong, M.J. (1985). Evaluating counselor effectiveness: A critical review of rating scale instruments. Journal of Counseling Psychology, 32, 597616.

Rempel, J.K., Holmes, J.G., \& Zanna, M.P. (1985). Trust in close relationships. Journal of personality and social Psychology, 49, 95-112.

Rice, L., \& Greenberg, L. (1984). Patterns of change: Intensive analysis of psychotherapy process. New York: Guilford Press. 
Rogers, C.R. (1957). The necessary and sufficient conditions

of therapeutic personality change. Journal of Consulting psychology, 21, 95-103.

Roll, W.V., Schmidt, L.D., \& Kaul, T.J. (1972). Perceived

interviewer trustworthiness among black and white

convicts. Journal of Counseling Psychology, 19, 537-541.

Rotter, J.B. (1971). Generallzed expectancies for

interpersonal trust. American Psychologist, 26, 443-452.

Safran, J., Crocker, P., McMain, S., \& Murray, P. (1990).

Therapeutic alliance rupture as a therapy event for

empirical investigation. Psychotherapy, 27, 154-165.

Saunders, S.M., Howard, K.I., \& Orlinsky, D.E. (1989). The

therapeutic bond scales: Psychometric characteristics and relationship to treatment effectiveness. Psychological

Assessment: A Journal of Consulting and clinical

Psychology, 1, 323-330.

Schiffman, S. (1987). Clinical psychology training and

psychotherapy interview performance. Psychotherapy, 24, $71-84$.

Scofield, M.E., \& Yoxtheimer, L. (1983). Psychometric issues

in the assessment of clinical competencies. Journal of

Counseling Psychology, 30, 413-420.

Smith, M.L., Glass, G.V., \& Miller, T.I. (1980). The benefits of psychotherapy. Baltimore: Johns Hopkins University Press. 
stevenson, J.F., \& Norcross, J.C. (1987). Current status of training evaluation in clinical psychology. In B.A. Edelstein \& E.S. Berler (Eds.), Evaluation and accountability in clinical training (pp. 77-115). New York: Plenum Press.

strong, S.R. (1968). Counseling: An interpersonal influence process. Journal of Counseling Psychology, 15, 215-224. strong, S.R., \& Schmidt, L.D. (1970). Trustworthiness and influence in counseling. Journal of Counseling psychology, 17, 197-204.

strupp, H.J. (1973). Psychotherapy: Clinical, research, and theoretical issues. New York: Aronson. Strupp, H.J. (1977). A reformulation of the dynamics of the therapist's contribution. In A.S. Gurman \& A.M. Razin (Eds.), Effective psychotherapy: A handbook of research (pp. 1-22). New York: Pergamon.

strupp. H., \& Hadley, S. (1979). Specific versus nonspecific factors in psychotherapy: A controlled study of outcome. Archives of General Psychiatry, 36, 1125-1126. Thompson, A. (1986). Changes in counseling skills during graduate and undergraduate study. Journal of counseling Psychology, 33, 65-72.

Tyler, E. (1965). Comment. Journal of Counseling Psychology, 12. $10-16$. 
Zamostny, K.P., Corrigan, J.D., E Eggert, M.A. (1981).

Replication and extension of social influence processes in counseling: A field study. Journal of Counseling psychology, 28, 481-489. 
Appendix A

Interview outline 


\section{Interview outline}

Initial Global Impression:

Tell me what comes to mind when you think of what makes a therapist trustworthy?

In what ways can a therapist act to gain your trust?

Give me some examples.

What else besides (subject response) makes you think makes a therapist trustworthy?

Is there anything else?

What is it about what a therapist says, how $s /$ he says it, or how $s /$ he generally acts that makes you trust him/her?

Think about past experiences that you have had, either with therapists or with other people for whom you were deciding to trust.

Can you give me an another example of what a therapist could say or do to gain your trust?

What is it about the way in which they act?

How can you tell if a therapist is being honest with you?

\section{Confidentiality:}

What is it about the things a therapists says or how s/he acts that leads you to know that what you talk about will be kept confidential.

\section{Self-Disclosure:}

What is it about the things a therapist says to you or how $s /$ he acts that makes you feel comfortable enough to talk about very sensitive and personal things.

Can you give me an example of something specific that they would say or something specific about the way in which they acted?

What else might they say or do to make you feel like opening up? 
y/sensitivity/non-judgmentalness:

ght a therapist talk/act with you that would suggest that $s$ concerned about you and won't judge what you say? ehaviors suggest that $s /$ he is caring and concerned for

giving:

s it about the things a therapist says to you or how $s$ /he chat makes you feel that the advice they give you was ole.

is it about what a therapist says, how s/he says it, or he generally acts that makes you follow through with er advice or suggestions.

is it about the things that your therapist says to you or he acts that makes you think that $s /$ he is an effective ist.

ou give me some specific examples of how they behave with

\section{erbals:}

me what role such things as a therapist's eye contact, posture, head movements, use of hands, etc. play in you ing that a therapist can be trusted.

ust :

is it about the way a therapist might act to lose your

ou give me some specific examples?

rn to Honesty; Confidentiality; Self-disclosure and re about behaviors suggesting the absence of these] 


\section{Appendix B}

Demographic Sheet and stage II Rating Materials 


\section{Information Sheet}

1. Date:

2. Age:

3. Sex:

M F

4. Race:

White

5. Marital Status:

Married

NonWhite (Specify:

Separated

Widowed

Divorced Never Married

6. Occupation: Full-time job Part-time job Unemployed Student

7. Religion: Catholic Protestant Jewish None Other (Specify:

8. Bducation: Under 12 th grade High School/G.E.D. College (Specify years Degree (s) (Specify:

9. Pamily Income:

under 10,000
$10,001-20,000$
$20,001-30,000$

$30,001-40,000$
$-40,001-50,000$
over 50,000

10. Therapy Experience:

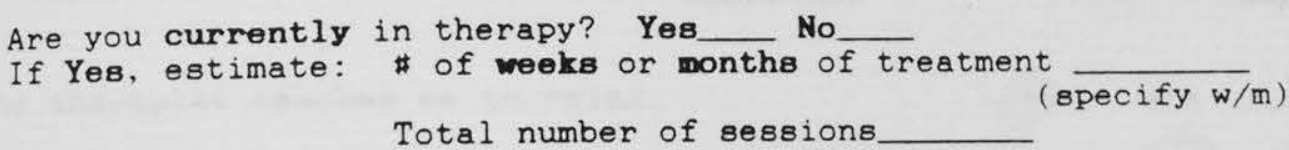

Have you ever in the past been in outpatient treatment with a mental health therapist (i.e., psychiatrist, social worker, psychologist)? No

How many different times How many different therapists Total time in treatment (please estimate \& specify \# of weeks or months)

Have you ever been hospitalized for emotional problems? $\mathbf{Y}_{\text {__ }} \mathbf{N}$ Is today your lst appointment here for therapy? $\mathrm{Y}_{-} \mathrm{N}_{-}$ 


\section{INSTRUCTIONS FOR RATING ITEMS}

We are interested in learning whether certain therapist behaviors We are interese decrease, or are otherwise not related to the "trustworthiness increaserapist. Please read the instructions and study the examples below.

on the following pages is a list of statements that describe a variety of therapist behaviors. As you read each statement, think of a therapist doing or saying what is described. Then:

1.) Circle the:

"+" -if you think the behavior would make a therapist appear more trustworthy; then rate how important that behavior is in terms of making a therapist appear more trustworthy.

$$
\text { Or, circle }
$$

"." -if you think the behavior would make a therapist appear less trustworthy; then rate how important that behavior is in terms of making a therapist appear less trustworthy.

$$
\text { Or, circle }
$$

" $n / a "$ - if the behavior is not related to trustworthiness. If $\mathrm{n} / \mathrm{a}$ is circled, do not rate the importance of the behavior.

\section{PLEASE STUDY THBSE BXAMPLES:}

+ = increases trustworthiness

+ decreases trustworthiness

$\mathrm{n} / \mathrm{a}=$ not related

\section{somewhat $\begin{array}{llllll}1 & 4 & 5 & 6 & \\ & & & & \text { extremely }\end{array}$

important important

The therapist teaches me to relax.

The therapist has interesting art in his office.

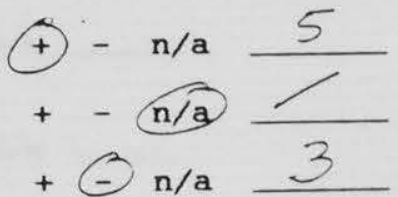

The therapist wears very unusual clothes.

2.) We are not asking you to rate your own therapist (if you have one). Just think of therapists in general.

*Please note that the pronouns "he, him, \& his" are used in place of "she, her, \& hers". The behaviors apply to both sexes. 
$+=$ increases tmutworthiness

$+=$ decreases tmustworthiness

$n / a=$ not related
RATIIG SCAIR

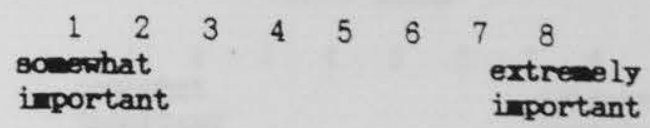

1. He indicates that he won't judge me or criticize me no matter what I tell him.

2. He suggests that my problems are not as bad as the problems most other people have.

3. He takes time to think about the things I tell him before answering me.

4. He changes topics when I ask him something about himself.

5. If something is bothering me he lets me talk about it and get it off my chest.

6. He asks many questions that are not related to the problem(s) I am seeing him for.

7. He tells me that he is encouraged or pleased by the way I am dealing with thing 3 .

8. He indicates that I have certain thoughts or feelings that are wrong or bad.

9. When he tells me his view of me, he balances the positives with the negatives.

10. He tells me things about himself so that I can get to know him better.

11. He asks me to remind him of things I've already told him.

12. He asks for my opinion or feelings about things he says.

13. He indicates that he respects me despite the problems I have.

14. He disagrees with me about what we should talk about.

15. He talks so much that I don't get a chance to say as much as I would like.

16. He indicates that I should ask questions if what he says is not clear.

17. He tells me that I am wrong or disapproves of certain things I say or do.
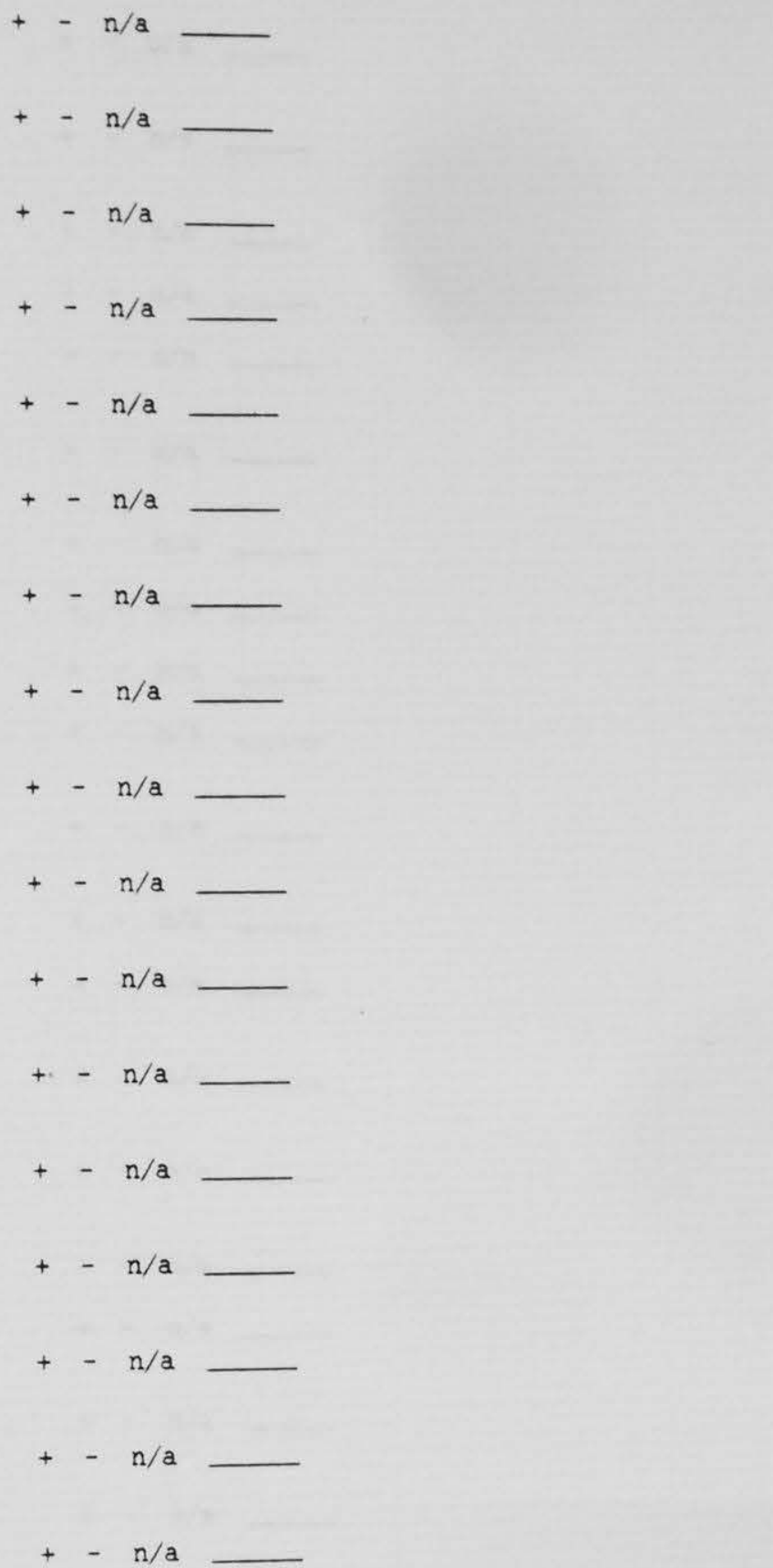
$+=$ increases trustworthiness

- = decreases tmustworthiness

$n / a=$ not related

\section{RATING SCALB}

$\begin{array}{ccccccccc}1 & 2 & 3 & 4 & 5 & 6 & 7 & 8 \\ \text { somewhat } & & & & & \begin{array}{l}8 \\ \text { extremely } \\ \text { important }\end{array} \\ \text { important } & & & & & \end{array}$

18. He indicates that he is hopeful I will get better.

19. He uses his sense of humor to lighten things up a bit.

20. His voice is harsh.

21. His words come out with pauses and hesitations.

22. He indicates that "we" will work together to try to solve my problems.

23. He states back to me things that I tell him in order to be sure he understands me.

24. He makes "small talk" about every day things.

25. His voice is pleasant.

26. He gives me wrong information.

27. He nods his head as a way of agreeing with me when I'm talking.

28. He indicates that my concerns or problems are silly.

29. He misstates things that I have told him.

30. He gives me advice or suggestions about how to deal with my problems.

31. He says that what we talk about will be kept private.

32. He tells me his view of my problems and what it will take for me to feel better.

33. He uses words too big for me to understand.

34. He gives me the same advice even though it hasn't worked for me in the past.

35. He talks too rapidly for me to easily follow what he is saying.

36. He talks about his own experiences if they relate to what I'm going through.

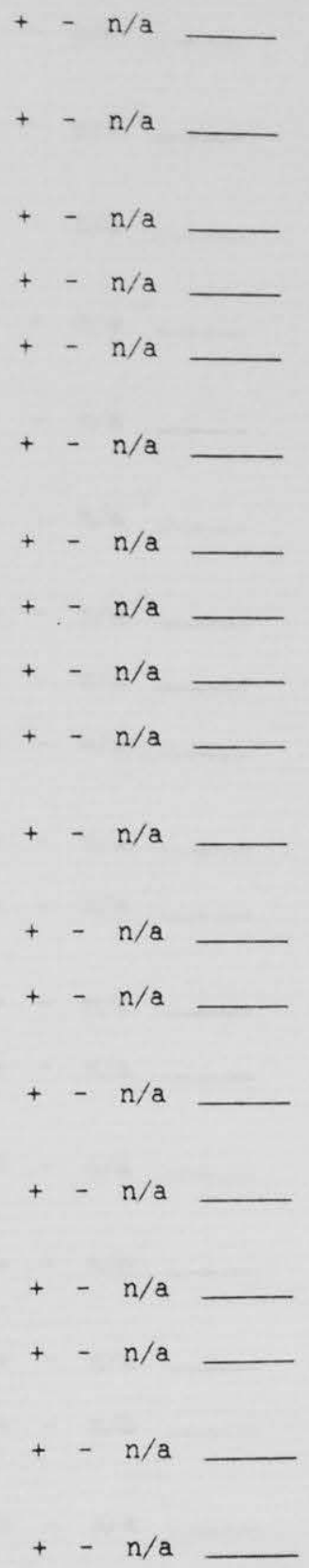


- increases tmistworthiness

$+=$ decreases tmustworthiness

$n / a=$ not related
RATING SCALS

$\begin{array}{llllllll}1 & 2 & 3 & 4 & 5 & 6 & 7 & 8 \\ \text { somewhat } & & & & & \begin{array}{l}\text { extremely } \\ \text { important }\end{array}\end{array}$

37. He makes decisions that affect me without

$+-n / a$ asking for my input.

38. He indicates that for therapy to work, we need to trust each other.

39. He moves some part of his body, like his hands or feet, a lot.

40. He says something encouraging to me when we part.

41. He will tell me that he thinks I may get hurt by something that I am planning to do.

42. He intermuts me without explaining or

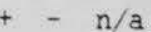

$+-n / a$

$+-n / a$

$+n / a$

$+-n / a$ apologizing.

43. He forgets things that I tell him.

44. He agrees with just about everything I say.

45. He indicates that he (or somebody) will be available if I really need to talk.

46. He leans slightly forward in his chair.

47. He is amused by things about me that I don't find funny.

48. He looks at his watch.

49. He finishes my sentences before I can say what I am thinking.

50. He is easily distracted and loses his train of thought.

51. He indicates that for therapy to work, it is important that I trust him.

52. He is quiet and hardly says anything.

53. He looks at different parts of my body, other than my eyes.

54. He says that he will be able to help me with my problems.

55. He gives long and drawn out answers to even the simplest questions. 
$+=$ increases tmustworthiness

- = decreases trustworthiness

$n / a=$ not related

\section{RATING SCAIS}

$\begin{array}{cccccccc}1 & 2 & 3 & 4 & 5 & 6 & 7 & 8 \\ \text { somewhat } \\ \text { important }\end{array}$

56. When he first sees me he smiles and is warm.

57. When he gives me advice he will say, "why don t you try..." or "have you thought about..." rather than just telling me to do something.

58. He holds his eye contact when talking to me.

59. He touches me on the shoulder, arm, or other such place.

60. He suggests that the best way of doing things is his way.

61. He gives me information and tells me what he knows about the problems I have.

62. If he is late or there is an intermuption he will apologize.

63. He appears comfortable and relaxed.

64. He indicates that it is O.K. to say whatever I happen to be feeling or thinking.

65. He looks away when certain topics come up.

66. He shakes my hand when greeting or parting.

67. He remembers and brings up things that we ve talked about before.

68. He tells me what I should do if I need help in an emergency.

69. The expression on his face is serious and rarely changes.

70. He asks me how things are going for me in certain areas of my life, even if they are not related to the problem that brought me to him.

71. He is quick to smile.

72. He hurries the conversation along as if he was impatient with me.

73. He explains things to me in an overly simple way.

74. He talks in detail about other patients.

75. He raises his voice.

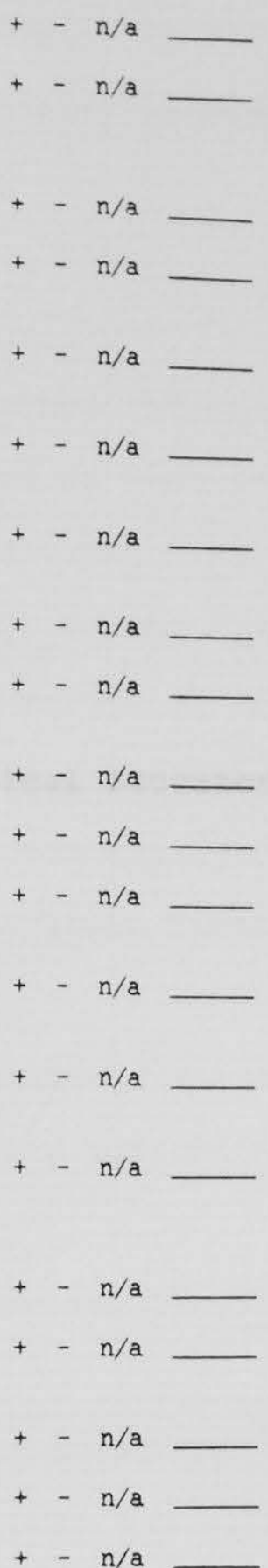


Appendix C

Item Rating Instructions for Clinical Educator Judges 
INSTRUCTIONS FOR RATING ITEMS

A large number of psychotherapy clients have read through this 1 ist of therapist behaviors and have rated each one as:

a) Positively associated with therapist trustworthiness;

b) Negatively associated with therapist trustworthiness; or,

c) Unrelated to trustworthiness.

I am interested now in gauging whether therapist trainees could, in fact, be coached or instructed to emit (or to not emit) the behaviors as described in each item. To this end, I would like for you to read each item and do the following:

1) If the "+" in the right hand column is circled, ask yourself whether you could get a trainee to reliably emit that behavior when appropriate. Indicate "YES" or "NO" in the space to the right of the item.

2) If the "-" is circled, ask yourself whether you could get a trainee to reliably not emit that behavior. Indicate "YES" or "NO" next to the item.

Granted, these behaviors are being rated out of context and the task is somewhat abstract. Merely ask yourself, if under appropriate training circumstances (i.e., motivated student, video equipment, etc.), these behaviors could be 
successfully trained. Please make no judgment regarding the clinical utility or appropriateness of training such behaviors. please review these examples:

\section{Item \#1:}

-He indicates that he won't judge me or criticize me no matter what I tell him.

(Could you get a trainee to consistently not judge or criticize a client regardless of what the client says?)

\section{Item \#2:}

-He suggests that my problems are not as bad as the problems most other people have. (could you get a trainee to not tell patients

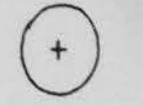
that their problems are "not as bad" as the problems of other people?) 
Appendix D

Percentage Agreement of Client Judges' Ratings of Each Item's Relevance to Trustworthiness 
Percent Agreement

I tem

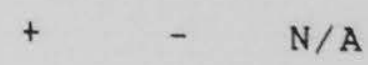

1. He indicates that he won't judge me or

90.9

4.5

4.5 criticize me no matter what I tell him.

2. He suggests that my problems are not as $\begin{array}{llll}12.1 & 66.7 & 21.2\end{array}$ bad as the problems most other people have.

3. He takes time to think about the things $92.4 \quad 1.5 \quad 6.1$ I tell him before answering me.

4. He changes topics when I ask him $\quad 9.1 \quad 71.2 \quad 19.7$ something about himself.

5. If something is bothering me he lets me $97.0 \quad 0.0 \quad 3.0$ talk about it and get it off my chest.

6. He asks many questions that are not $\quad \begin{array}{lllll}16.7 & 59.1 & 22.4\end{array}$ related to the problem(s) I am seeing him for.

7. He tells me that he is encouraged or $86.4 \quad 1.5 \quad 12.1$ pleased by the way I am dealing with things.

8. He indicates that I have certain thoughts $22.7 \quad 71.2 \quad 6.1$ or feelings that are wrong or bad. 
Percent Agreement

Item

$+\quad-\quad \mathrm{N} / \mathrm{A}$

9. When he tells me his view of me, he

$90.9 \quad 3.0 \quad 6.1$

balances the positives with the

negatives.

10. He tells me things about himself so that $\begin{array}{llll}57.6 & 15.6 & 25.8\end{array}$

I can get to know him better.

11. He asks me to remind him of things I've $\begin{array}{llll}12.1 & 75.8 & 12.1\end{array}$ already told him.

12. He asks for my opinion or feelings about $\begin{array}{llll}77.3 & 10.6 & 12.1\end{array}$ things he says.

13. He indicates that he respects me despite $81.9 \quad 4.5 \quad 13.6$ the problems I have.

14. He disagrees with me about what we should $16.7 \quad 63.6 \quad 18.7$ talk about.

15. He talks so much that I don't get a

$3.1 \quad 86.2 \quad 10.1$ chance to say as much as I would like.

16. He indicates that I should ask questions $97.0 \quad 0.0 \quad 3.0$ if what he says is not clear.

17. He tells me that I am wrong or does not $\begin{array}{llll}25.8 & 68.2 & 6.0\end{array}$ approve of certain things I say or do. 
Percent Agreement

I tem

$\mathrm{N} / \mathrm{A}$

18. He indicates that he is hopeful I will

77.3

7.6

13.1

get better.

19. He uses his sense of humor to lighten

$6.1 \quad 15.1$

things up a bit.

20. His volce is harsh.

$\begin{array}{lll}3.0 & 77.3 & 19.7\end{array}$

21. His words come out with pauses and

$6.148 .5 \quad 45.5$ hesitations.

22. He indicates that "we" will work

89.

6.1

4. 5 together to try to solve my problems.

23. He states back to me things that I tell

$92.4 \quad 3.1 \quad 4.5$ him in order to be sure he understands me.

24. He makes "small talk" about every day

$\begin{array}{lll}34.8 & 28.8 \quad 34.4\end{array}$ things.

25. His voice is pleasant.

$81.8 \quad 18.2 \quad 0.0$

26. He gives me wrong information.

$0.0 \quad 97.0 \quad 3.0$

27. He nods his head as a way of agreeing

$57.1 \quad 12.1 \quad 28.8$ with me when I'm talking.

28. He indicates that my concerns or

$0.0 \quad 95.5 \quad 4.5$ problems are silly.

29. He misstates things that I have told him. $1.592 .4 \quad 6.1$ 


\section{Percent Agreement}

I tem

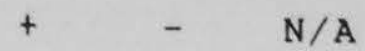

30. He gives me advice or suggestions about

89.4

9.1

1.5 how to deal with my problems.

31 He says that what we talk about will be

97.0

1.5

1.5 kept private.

32. He tells me his view of my problems and

$\begin{array}{lll}78.8 & 9.1 & 9.1\end{array}$ what it will take for me to feel better.

33. He uses words too big for me to

$0.0 \quad 72.7 \quad 27.3$ understand.

34. He gives me the same advice even though

$$
6.186 .3 \quad 7.6
$$

it hasn't worked for me in the past.

35. He talks too rapidly for me to easily

$$
0.0 \quad 74.2 \quad 25.8
$$

follow what he is saying.

36. He talks about his own experiences if

$66.7 \quad 27.2 \quad 6.1$ they relate to what I'm going through.

37. He makes decisions that affect me without asking for my input.

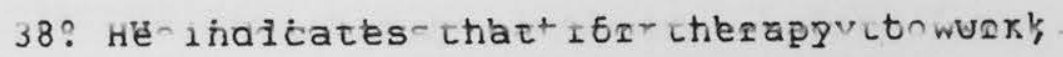
we need to trust each other.

39. He moves some part of his body, like his hands or feet, a lot. 
Percent Agreement

I tem

40. He says something encouraging to me when we part.

41. He'll tell me that he thinks I may get hurt by something that I am planning to do.

42. He interrupts me without explaining or apologizing.

43. He forgets things that I tell him.

44. He agrees with just about everything I say.

45. He indicates that he (or somebody) will be available if I really need to talk.

46. He leans slightly forward in his chair.

47. He is amused by things about me that I don't find funny.

48. He looks at his watch.

49. He finishes my sentences before I can say what I am thinking.

50. He is easily distracted and loses his train of thought.
$90.9 \quad 1.5 \quad 7.6$

$83.3 \quad 10.6 \quad 6.1$

$\begin{array}{lll}3.0 & 87.9 & 9.1\end{array}$

$\begin{array}{lll}4.5 & 86.4 & 9.1\end{array}$

$\begin{array}{lll}3.0 & 90.9 & 6.1\end{array}$

$92.5 \quad 4.5 \quad 3.0$

$\begin{array}{lll}34.8 & 4.5 & 60.6\end{array}$

$\begin{array}{lll}6.1 & 78.7 \quad 15.2\end{array}$

$0.0 \quad 72.7 \quad 27.3$

$\begin{array}{lll}1.5 & 84.8 & 13.7\end{array}$

$0.0 \quad 92.4 \quad 7.6$ 
Percent Agreement

Item

$\mathrm{N} / \mathrm{A}$

51. He indicates that for therapy to work,

$\begin{array}{lll}63.6 & 15.2 & 21.2\end{array}$

it is important that I trust him.

52. He is quiet and hardly says anything.

$\begin{array}{lll}10.6 & 78.8 & 10.6\end{array}$

53. He looks at different parts of my body,

$\begin{array}{lll}7.6 & 71.2 & 21.2\end{array}$ other than my eyes.

54. He says that he will be able to help me

$\begin{array}{lll}78.8 & 9.1 & 12.1\end{array}$ with my problems.

55. He gives long and drawn out answers to

$\begin{array}{lll}4.5 & 72.7 & 22.8\end{array}$ even the simplest questions.

56. When he first sees me he smiles and is

0.0

0.0 warm.

57. When he gives me advice he will say "why 92.4

0.0 7.6 don't you try..." or "have you thought about..." rather than just telling me to do something.

58. He holds his eye contact when talking $98.5 \quad 0.0 \quad 1.5$ to me.

59. He touches me on the shoulder, arm, or $\begin{array}{lll}51.5 & 28.8 & 19.7\end{array}$ other such place.

60. He suggests that the best way of doing $3.0 \quad 89.4 \quad 7.6$ things is his way. 
Percent Agreement

I tem

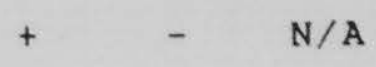

61. He gives me information and tells me

94.0

$4.5 \quad 1.5$ what he knows about the problems I have.

62. If he is late or there is an $92.4 \quad 1.5 \quad 6.1$ interruption he will apologize.

63. He appears comfortable and relaxed. $98.5 \quad 0.0 \quad 1.5$

64. He indicates that it is O.K. to say $98.5 \quad 0.0 \quad 1.5$ whatever I happen to be feeling or thinking.

65. He looks away when certain topics come $0.0 \quad 92.4 \quad 7.6$ up.

66. He shakes my hand when greeting or $60.6 \quad 4.5 \quad 34.9$ parting.

67. He remembers and brings up things that $97.0 \quad 1.5 \quad 1.5$ we've talked about before.

68. He tells me what I should do if I need $93.9 \quad 0.0 \quad 6.1$ help in an emergency.

69. The expression on his face is serious $6.1 \quad 69.7 \quad 24.2$ and rarely changes. 
Item

70. He asks me how things are going for me in certain areas of my life, even if

they are not related to the problems

that brought me to him.

71. He is quick to smile.

72. He hurries the conversation along as if he were impatient with me.

73. He explains things to me in an overly simple way.

74. He talks about other patients.

75. He raises his voice.
Percent Agreement

$+\quad-\quad$ N/A $\begin{array}{rrr}80.3 & 7.6 & 12.1 \\ 0.0 & 95.5 & 4.5\end{array}$

$13.7 \quad 66.7 \quad 16.7$

$\begin{array}{lll}1.5 & 92.4 \quad 6.1\end{array}$

$\begin{array}{lll}1.5 & 78.8 & 19.7\end{array}$ 


111

Appendix E

Mean Importance Ratings Based on Client Judges' Evaluations 
1. He indicates that he won't judge me or

criticize me no matter what I say.

3. He takes time to think about the things $\begin{array}{llll}6.15 & 1.74 & 60\end{array}$ I tell him before answering me.

5. If something is bothering me he lets me $\begin{array}{ccc}6.79 & 1.35\end{array}$

talk about it and get it off my chest.

7. He tells me that he is encouraged or

pleased by the way I am dealing with

things.

9. When he tells me his view of me, he

balances the positives with the

negatives.

11. He asks me to remind him of things I've $\begin{array}{lllll}4.74 & 2.25 & 50\end{array}$ already told him.

12. He asks for my opinion or feelings about $5.40 \quad 1.92 \quad 50$ things he says.

13. He indicates that he respects me despite $\begin{array}{llll}6.43 & 2.10 & 53\end{array}$ the problems I have.

15. He talks so much that I don't get a $\quad 6.27 \quad 1.73 \quad 55$ chance to say as much as I would like.

16. He indicates that I should ask questions $6.27 \quad 2.12 \quad 63$ if what he says is not clear. 
Item

Mean $\quad \underline{S D} \quad \underline{N}$

18. He indicates that he is hopeful I will $\quad 6.31 \quad 1.76 \quad 50$ get better.

19. He uses his sense of humor to lighten $\quad \begin{array}{llll}5.82 & 1.96 & 51\end{array}$ things up a bit.

20. His voice is harsh.

22. He indicates that "we" will work

$5.02 \quad 2.28 \quad 50$

together to try to solve my problems.

23. He states back to me things that I tell $5.82 \quad 2.00 \quad 61$ him in order to be sure he understands me.

25. His voice is pleasant.

$5.51 \quad 2.22 \quad 53$

26. He gives me wrong information.

$6.62 \quad 2.12 \quad 63$

28. He indicates that my concerns or

$6.44 \quad 2.01 \quad 62$

problems are silly.

29. He misstates things that I have said. $\quad 6.03 \quad 2.08 \quad 60$

30. He gives me advice or suggestions about $\begin{array}{llll}6.03 & 1.98 & 58\end{array}$ how to deal with my problems.

31. He says that what we talk about will be $7.13 \quad 1.53 \quad 62$ kept private.

32. He tells me his view of my problems and $6.17 \quad 2.00 \quad 52$ what it will take for me to feel better.

34. He gives me the same advice even though $\begin{array}{llll}5.31 & 2.05 & 55\end{array}$ it hasn't worked for me in the past. 
Item

Mean $\quad \underline{S D} \quad \underline{N}$

18. He indicates that he is hopeful I will $\quad 6.31 \quad 1.76 \quad 50$ get better.

19. He uses his sense of humor to lighten

$5.82 \quad 1.96$

51

things up a bit.

20. His voice is harsh.

$5.02 \quad 2.28 \quad 50$

22. He indicates that "we" will work

$5.92 \quad 2.19 \quad 59$

together to try to solve my problems.

23. He states back to me things that I tell $5.82 \quad 2.00 \quad 61$

him in order to be sure he understands

me.

25. His voice is pleasant.

$5.51 \quad 2.22 \quad 53$

26. He gives me wrong information.

$6.62 \quad 2.12 \quad 63$

28. He indicates that my concerns or

$6.44 \quad 2.01$

62

problems are silly.

29. He misstates things that I have said.

$6.03 \quad 2.08 \quad 60$

30. He gives me advice or suggestions about

$6.03 \quad 1.98 \quad 58$ how to deal with my problems.

31. He says that what we talk about will be $\begin{array}{llll}7.13 & 1.53 & 62\end{array}$ kept private.

32. He tells me his view of my problems and $\begin{array}{llll}6.17 & 2.00 & 52\end{array}$ what it will take for me to feel better.

34. He gives me the same advice even though $\begin{array}{llll}5.31 & 2.05 & 55\end{array}$ it hasn't worked for me in the past. 
Mean

$\underline{S D}$

$\underline{\mathrm{N}}$

37. He makes decisions that affect me

$\begin{array}{lll}6.46 & 1.82 \quad 59\end{array}$

without asking for my input.

38. He indicates that for therapy to work, $6.41 \quad 1.95 \quad 54$ we need to trust each other.

40. He says something encouraging to me $5.61 \quad 2.25 \quad 59$ when we part.

41. He'11 tell me that he thinks I may get $5.34 \quad 2.14$ 54 hurt by something that I am planning to do.

42. He interrupts me without explaining or apologizing.

43. He forgets things that I tell him. $5.36 \quad 2.28 \quad 56$

44. He agrees with just about everything I

$4.90 \quad 2.10 \quad 59$
say.

45. He indicates that he (or somebody) will $6.55 \quad 1.80 \quad 60$ be available if I really need to talk.

47. He is amused by things about me that I don't find funny.

49. He finishes my sentences
say what I am thinking.

50. He is easily distracted and loses his train of thought.

52. He is quiet and hardly says anything. 
Item

Mean $\quad \underline{S D} \quad \underline{N}$

54. He says that he will be able to help me $\begin{array}{llll}5.25 & 2.38 & 51\end{array}$ with my problems.

56. When he first sees me he smiles and is $5.68 \quad 1.89 \quad 65$ warm.

57. When he gives me advice he will say "why $5.90 \quad 1.78 \quad 60$ don't you try..." or "have you thought about..." rather than just telling me to do something.

58. He holds his eye contact when talking to me.

60. He suggests that the best way of doing $\begin{array}{lll}5.19 & 2.32 & 58\end{array}$ things is his way.

61. He gives me information and tells me $5.94 \quad 1.80$ what he knows about the problems I have.

62. If he is late or there is an $\begin{array}{lll}5.72 & 2.03 \quad 60\end{array}$ interruption he will apologize.

63. He appears comfortable and relaxed. $5.90 \quad 2.17 \quad 59$

64. He indicates that it is O.K. to say

$6.73 \quad 1.87 \quad 64$
whatever I happen to be feeling or thinking.

65. He looks away when certain topics come 5.10 up. 
67. He remembers and brings up things that $6.25 \quad 1.82 \quad 63$ I have talked about before.

68. He tells me what I should do if I need $6.34 \quad 2.02 \quad 61$ help in an emergency.

70. He asks me how things are going for me $4.96 \quad 2.06 \quad 56$ in certain areas of my life, even if they are not related to the problems that brought me to him.

71. He is quick to smile. $\quad 5.38 \quad 2.08 \quad 53$

72. He hurries our conversation along as if $\quad \begin{array}{llll}6.03 & 2.07 & 62\end{array}$ he were impatient with me.

74. He talks about other patients. $\quad \begin{array}{lll}6.68 & 2.34 & 60\end{array}$ 75. He raises his voice. $\quad 5.04 \quad 2.55 \quad 51$ 
Appendix $F$

Therapist Behavior Rating Scale (TBRS) 


\section{Therapist Behavior Rating scale}

The statements on the following pages describe a variety of theraplst please rate the extent to which you follow by a six point scale (shown below). it applies to your therapist's behavior therapist to say and do during treatment sessions.

If you completely agree with the statement, circle 1. If you completely disagree with the statement, circle 6 . Please use the numbers between these two extremes $1 \mathrm{f}$ they fit more closely with what you have observed your
therapist to say or do in treatment sessions.

\begin{tabular}{cccccc}
\hline $\begin{array}{c}\text { Completely } \\
\text { Agree }\end{array}$ & $\begin{array}{c}\text { Strongly } \\
\text { Agree }\end{array}$ & Agree & Disagree & $\begin{array}{c}\text { Strongly } \\
\text { Disagree }\end{array}$ & $\begin{array}{c}\text { Completely } \\
\text { Disagree }\end{array}$ \\
1 & 2 & 3 & 4 & 5 & 6 \\
\hline
\end{tabular}

YOUR RATINGS WILL BE KEPT CONFIDENTIAL. THEY WILL NOT BE SHOWN TO YOUR THERAPIST AND WILL BE USED ONLY FOR RESEARCH PURPOSES. PLEASE BE SURE TO RATE EACH STATEMENT, THANK YOU. 


\section{Completely strongly Agree Agree \\ 1 \\ 2 \\ Agree \\ Disagree \\ 2. \\ The therapist indicates that $s /$ he respects}

Strongly

Disagree

Completely

Disagree 5

me despite the problems I have.

$1 \quad 2 \quad 3 \quad 4 \quad 5 \quad 6$

2. The therapist indicates that my concerns or problems are silly.

3. When the therapist first sees me $s /$ he generally smiles and is warm.

4. The therapist holds his/her eye contact when talking to me.

5. The therapist is easily distracted and

loses his/her train of thought.

6. The therapist takes time to think about the things I say before answering me.

7. The therapist gives me wrong information.

8. If something is bothering me the therapist let's me talk about it and get it off my chest.

9. The therapist hurries our conversations along as if $s / h e$ was impatient with me.

10. The therapist indicates that for therapy to work, we need to trust each other.

11. The therapist talks so much that I don't get a chance to say as much as I would like.

12. The therapist tells me his/her view of ny problems and what it will take for me to feel better.

13. The therapist indicates that $s /$ he is hopeful that I will get better.

14. The therapist gives me advice or suggestions about how to deal with my problems.

15. The therapist tells me what I should do if I need help in an emergency.

16. The therapist misstates things that I have said.

17. The therapist indicates that $s /$ he won't judge me or criticize me no matter what I say.

18. The therapist indicates that I should ask questions if what s/he says is not clear.

19. The therapist makes decisions that affect me without asking for my input.

20. The therapist remembers and brings up things that I have talked about before. 
Appendix G

Client-Completed Rating Materials: (CRF-S; Likert-type Ratings) 
Listed below are a number of characteristics, followed by a seven-point scale that ranges from "not very" to "very." please mark an of the counselor on the scale that best represents your lhat you just saw. For example:

FUNNY

not very $X$ :

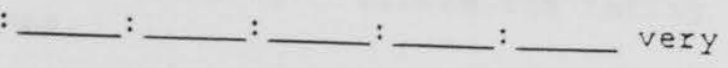

WELL DRESSED

not very :

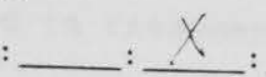
very

These ratings might show that the therapist did not joke around much, but was dressed well. While all of the following characteristics we ask you to rate are desirable, therapists may differ in their strengths. We are interested in knowing how you view these differences.

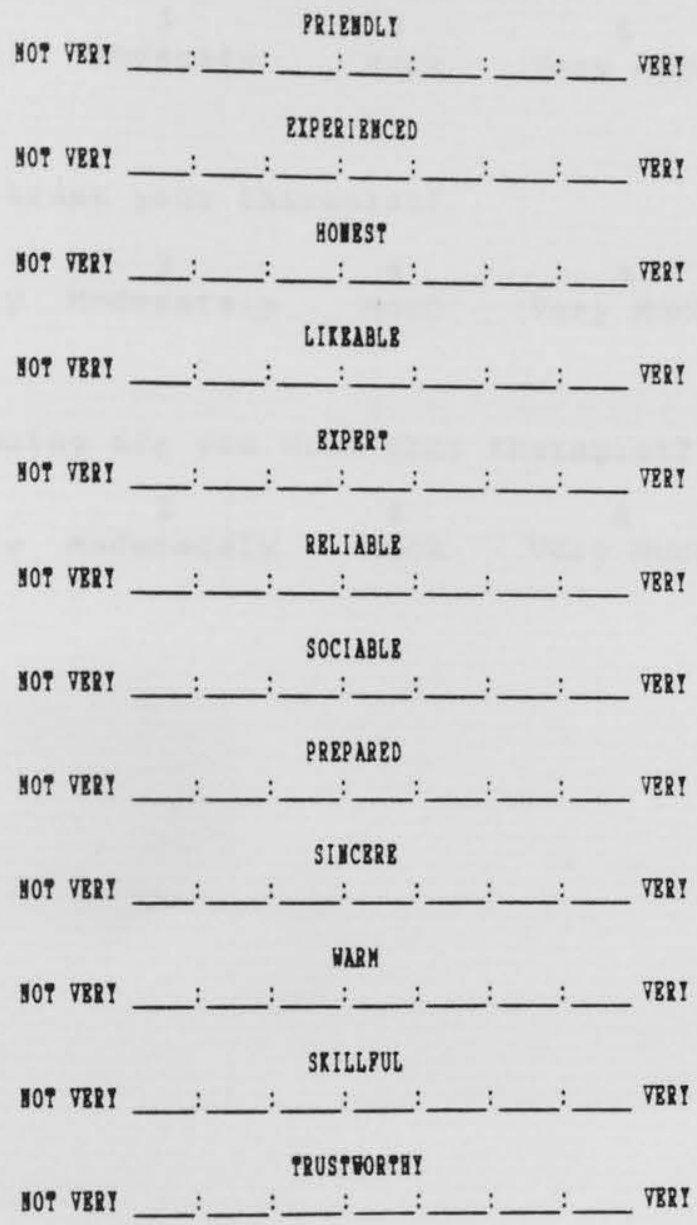


The following ratings are to be made in reference to your current therapy situation and treatment relationship. Circle the rating
that best describes your response.

1.) How much improvement have you achieved in treatment so far?

$\begin{array}{cccccc}1 & 2 & 3 & 4 & 5 & 6 \\ \begin{array}{c}\text { Not at All } \\ \text { Improved }\end{array} & \text { Slight } & \text { Moderate } & \text { Much } & \text { Very Much } & \begin{array}{c}\text { Extremely } \\ \text { Improved }\end{array}\end{array}$

2.) What is the current severity of the problems that initially led you to seek treatment?

$\begin{array}{cccccc}1 & 2 & 3 & 4 & 5 & 6 \\ \begin{array}{c}\text { Not at All } \\ \text { Severe }\end{array} & \text { Slight } & \text { Moderate } & \text { Much } & \text { Very Much } & \begin{array}{c}\text { Extremely } \\ \text { Severe }\end{array}\end{array}$

3.) How much do you trust your therapist?

Minimally

Trusting

$\begin{array}{ccc}2 & 3 & 4 \\ \text { Slightly } & \text { Moderately } & \text { Much }\end{array}$

Much Very Much

6

Extremely

Trusting

4.) How open and sharing are you with your therapist?

$\begin{array}{lccccc}1 & 2 & 3 & 4 & 5 & 6 \\ \begin{array}{l}\text { Minimally Slightly } \\ \text { Open/Sharing }\end{array} & \text { Moderately } & \text { Much } & \text { Very Much } & \begin{array}{l}\text { Extremely } \\ \text { Open/Sharing }\end{array}\end{array}$


Appendix $\mathrm{H}$

Therapists' Rating Materials 
Therapist I.D.

\section{Therapist Rating Pore}

1. Last 4 SSN digits of patient:

2. First Initial of patient's name:

4. Session date when Rating

scales were provided to patient:

5. Approximate start of $\mathrm{Tx}$. With patient: Month

3. Patlent's sex: M F

6. ( ) Approximate or ( ) Actual number of sessions:

7. Patlent's Dlagnoses: Axis I:

Axis I I :

1.) How much improvesent has this patient achieved in treatment so far?

$\begin{array}{cccccc}1 & 2 & 3 & 5 & 5 & 6 \\ \text { Not at All } & \text { Slight } & \text { Moderate } & \text { Much } & \text { Very Much } & \begin{array}{c}\text { Extremely } \\ \text { Improved }\end{array}\end{array}$

2.) What is the current severity of problems that initially led this patient to seek treatment?

\begin{tabular}{|c|c|c|c|c|c|}
\hline 1 & 2 & 3 & 4 & 5 & 6 \\
\hline $\begin{array}{l}\text { Not at All } \\
\text { Severe }\end{array}$ & slight & Moderate & Much & Very Much & $\begin{array}{c}\text { Extremely } \\
\text { Severe }\end{array}$ \\
\hline
\end{tabular}

3.) How much does this patient trust you?

1

MInlmally

Trusting

${ }^{2}$ slightly Moderately Much very ${ }^{3}$ Much

6

Extremely Trusting

4.) How open and sharing is this patient with you?

1

Minimally slightly Moderately Open/Shar Ing
Much Very Much

6 Extremely Open/Sharing 
Appendix I

Factor Labels, Items, and Item Loadings 


\section{Factor I: Positive Regard/Interest}

(3) When the therapist first sees me $s /$ he .70 generally smiles and is warm.

(19) The therapist makes decisions that affect me without asking for my input.

(4) The therapist holds his/her eye contact when talking to me.

(20) The therapist remembers and brings up things .58 that I have talked about before.

(8) If something is bothering me the therapist .58 let's me talk about it and get it off my chest.

(6) The therapist takes time to think about the things I say before answering me.

(17) The therapist indicates that $s /$ he won't judge $\quad .50$ me or criticize me no matter what I say.

(1) The therapist indicates that $s /$ he respects me despite the problems I have.

\section{Factor II: Incompetence/Disrespect}

(11) The therapist talks so much that I don't get .75 a chance to say as much as I would like.

(7) The therapist gives me wrong information. 75

(5) The therapist is easily distracted and .70 loses his/her train of thought. 
(Factor I continued)

(9) The therapist hurries our conversations along .68 as if $s /$ he was impatient with me.

(16) The therapist misstates things that I have said. .48

(2) The therapist indicates that my concerns or .36 problems are silly.

\section{Factor III: Directive/structuring}

(12) The therapist tells me his/her view of my

problems and what it will take for me to feel better.

(14) The therapist gives me advice or suggestions about how to deal with my problems.

(18) The therapist indicates that I should ask questions if what $s /$ he says is not clear.

(13) The therapist indicates that $s /$ he is hopeful that I will get better.

(15) The therapist tells me what I should do if

I need help in an emergency.

(10) The therapist indicates that for therapy to work, we need to trust each other. 


\section{ABSTRACT}

The purpose of the present study was to develop a clientcompleted rating scale to measure a set of therapist behaviors that contribute to clients' perceptions of therapists' trustworthiness. Presently, the few available instruments that target the trustworthiness construct are of limited psychometric integrity. Further, the content and format of these measures limit their usefulness for therapist training and evaluation purposes. Construction and evaluation of the Therapist Behavior Rating Scale (TBRS) proceeded in three stages. Stage I involved the development of a large pool of items based on interviews with psychotherapy consumers and on the adaptation of items from existing therapist and therapy process rating scales. Stage I involved refinement of the scale by identifying the items of most relevance and importance to trustworthiness. This was accomplished through a several stage process involving judgments and evaluative ratings provided by psychotherapy clients and experienced therapist educators. Stage II involved a preliminary psychometric evaluation of the 20-item TBRS. In this stage, estimates of the scale's internal consistency, test-retest reliability, and convergent, construct, and discriminant validity were calculated. To this end, 138 clients rated their therapists with the TBRS and they also completed several other measures of therapy process and treatment variables. Therapists, likewise, provided ratings of the same therapy 
process and treatment variables. From a reliability perspective, the TBRS demonstrated very satisfactory alpha and test-retest coefficients. Satisfactory evidence of convergent validity was demonstrated by the significant association between TBRS total scores and clients' ratings of trust in their therapists. Satisfactory evidence of construct validity was suggested by the significant associations between TBRS total scores and clients' ratings of self-disclosure, treatment gains, and a commonly used measure of positive therapist characteristics. Discriminant validity was suggested by the absence of significant associations between TBRS total scores and variables lacking a clear conceptual relationship to trustworthiness. An exploratory-descriptive factor analysis of the TBRS revealed a structure consisting of three readily interpretable dimensions: Positive Regard/Interest, Incompetence/Disrespect, and Directive/Structuring responses. The results are discussed in terms of the TBRS' potential utility in clinical, research, and teaching contexts. 
APPROVAL OF EXAMINING COMMITTEE
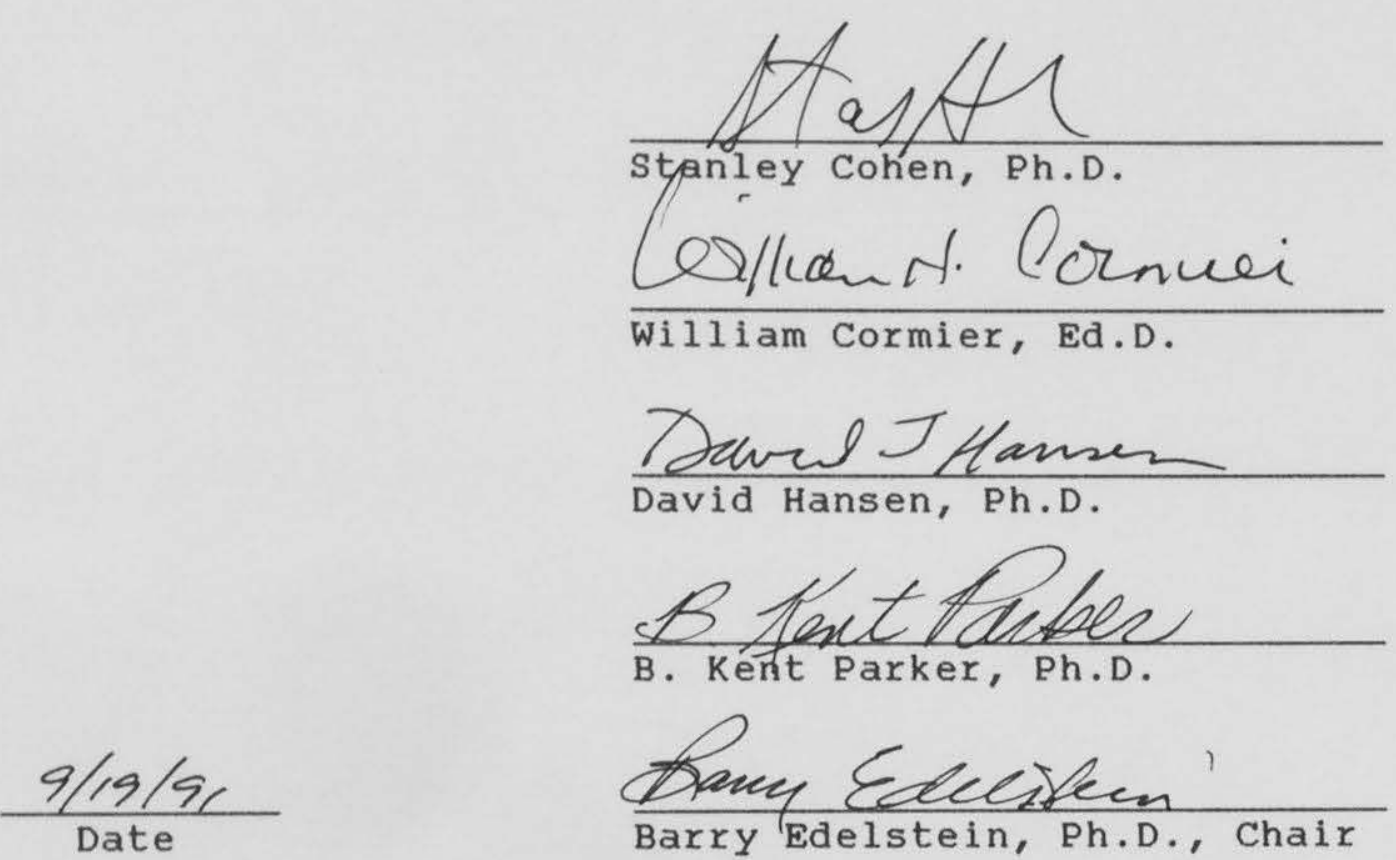


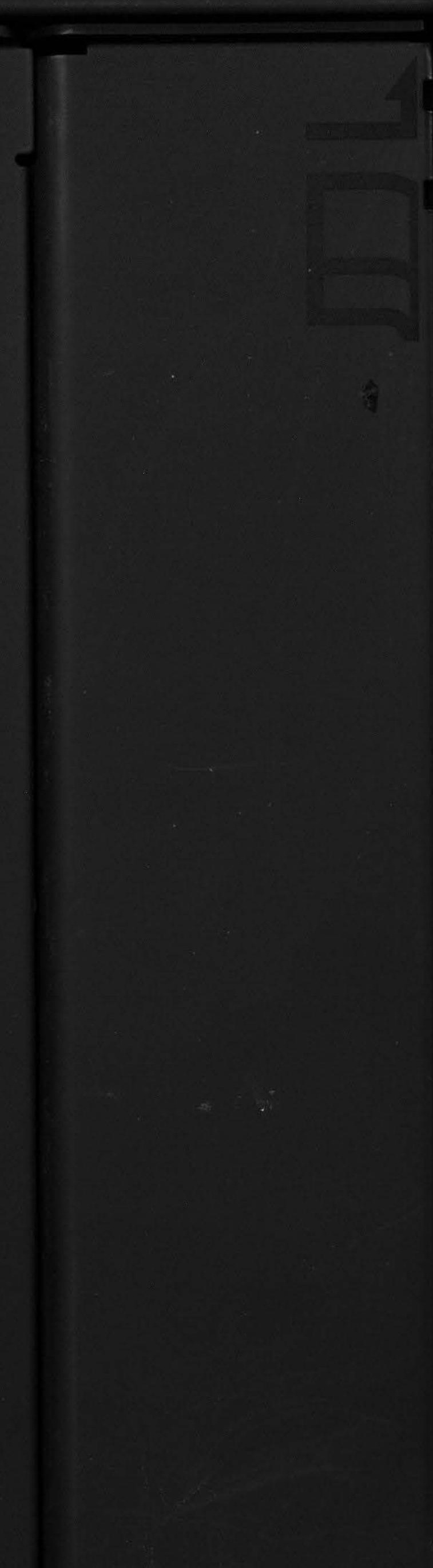

